\title{
A cost-effectiveness analysis model of Preventicus atrial fibrillation screening from the point of view of statutory health insurance in Germany
}

\author{
Ralf Birkemeyer ${ }^{1}$, Alfred Müller ${ }^{2}$, Steffen Wahler ${ }^{3^{*}}$ (D) and Johann-Matthias von der Schulenburg ${ }^{4}$
}

\begin{abstract}
Background: With atrial fibrillation (AF) the risk of stroke is 4.2-fold increased to a comparable population without AF. This risk decreases by up to $70 \%$ if AF is detected early enough and effective stroke preventive measures are taken as recommended by international guidelines. Long-term studies found large number of subjects with undiagnosed AF. Preventicus Heartbeats" is a hands-on screening tool for use on smartphone to diagnose AF with high sensitivity and specificity. The aim of this study is to research the cost-effectiveness of systematic screening for AF with this smartphone application.
\end{abstract}

Method: Employing a Markov model we analysed the cost-effectiveness of the "Preventicus Heartbeats" screening for Germany, i.e. from the perspective of German statutory sick funds.

Results: For a cohort of 10,000 insured 75-year-old the use of the diagnostic app could avoid 60 strokes in the remaining lifetime thereof 32 strokes in the next four years. Former models have applied similar cohorts. The same cohort showed an increase in quality-adjusted life years (QALY) in the remaining lifetime of 165 QALYs in the scenario with screening versus.

without screening and a decrease in discounted lifetime costs (including risk compensation effects) of $€ 129$ per participant (€148 for male, €114 for female participants).

Conclusions: The modelling demonstrates the health benefits and economic effects of an implementation of a systematic screening on AF with "Preventicus Heartbeats", given the perspective of the German payer, the statutory health care system.

Keywords: Atrial fibrillation, Screening, Prevention of stroke, Cost-effectiveness analysis

\section{Background}

Annual costs of acute and follow-up treatment of strokes were $€ 6.5$ billion in 2015 in the German health care system. Thereof ischemic strokes alone accounted for $€ 5.1$ billion [1]. One hundred six thousand persons a year insured in German statutory sick funds suffer a first-time

\footnotetext{
* Correspondence: steffen.wahler@t-online.de

${ }^{3}$ St. Bernward GmbH, Friedrich-Kirsten-Straße 40, 22391 Hamburg, Germany Full list of author information is available at the end of the article
}

stroke and 66,000 insured persons a recurrent stroke [2]. Based on the Erlangen registry [3], calculated lifetime costs of a stroke are around $€ 43,000$. Epidemiological studies also noted that - mainly due to German demography - the lifetime prevalence has risen significantly since 1998 [4].

Atrial fibrillation (AF) is the most common arrhythmia of clinical significance [5]. It is a supraventricular tachyarrhythmia with uncoordinated activity of the atria and

C C The Author(s). 2020 Open Access This article is licensed under a Creative Commons Attribution 4.0 International License, which permits use, sharing, adaptation, distribution and reproduction in any medium or format, as long as you give appropriate credit to the original author(s) and the source, provide a link to the Creative Commons licence, and indicate if changes were made. The images or other third party material in this article are included in the article's Creative Commons licence, unless indicated otherwise in a credit line to the material. If material is not included in the article's Creative Commons licence and your intended use is not permitted by statutory regulation or exceeds the permitted use, you will need to obtain permission directly from the copyright holder. To view a copy of this licence, visit http://creativecommons.org/licenses/by/4.0/. The Creative Commons Public Domain Dedication waiver (http://creativecommons.org/publicdomain/zero/1.0/) applies to the data made available in this article, unless otherwise stated in a credit line to the data. 
frequencies between 350 to $600 \mathrm{bpm}$. Result is functional loss of activity of the atria with reduction of cardiac output [6]. AF is associated with increased morbidity, especially stroke and heart failure, and increased mortality [7-10] and constitutes a significant public health problem [11-13]. The prevalence of diagnosed AF is estimated $1 \%$ in Germany with increase in the old age $(8 \%$ in population above 80 years) [14].

Mainly discovered is AF in patients who seek medical treatment due to related clinical symptoms (palpitations, shortness of breath, etc.) or in previously asymptomatic patients after they have suffered a stroke which was possibly caused by cerebral embolism [5]. Due to the relatively short observation periods, e.g. only around $60 \mathrm{~s}$ with a usual resting ECG, some screening studies provide low detection rates of previously undetected AF.

The Swedish "Strokestop" study [15] with 75-yearold subjects discovered a previously undetected AF in $3.0 \%$ of subjects using phased ECG recordings during a two-week measurement. The presence of atrial fibrillation was already known in $9.3 \%$ of the subjects. Various similar studies aimed at the identification of previously undetected AF and reported a ratio of unknown to known AF between 20 and $45 \%$ increasing with age $[16,17]$.

Analyses of long-term data released in the 1980s and 1990s showed a significantly increased likelihood of a stroke in patients with AF [8]. It was demonstrated that in patients with atrial fibrillation the probability of an ischemic stroke was increased 4- to 5 -fold, but also AF is associated with higher mortality, and, if stroke occurs, AF patients suffer a significantly higher degree of disability, death and risk of a second stroke within 12 months compared to non-AF patients [18-22].

Anticoagulating agents to reduce the risk of stroke with AF have been in clinical use since the 1980s. Several studies found oral anticoagulation to reduce the risk of stroke by $65-80 \%$ in patients with AF [23, 24]. Guidelines therefore require mandatory prevention with anticoagulants in AF patients with additional risk factors [25]. Vitamin $\mathrm{K}$ antagonists and antiplatelet agents have been increasingly replaced by direct (or "non-vitamin K antagonist") oral anticoagulants (NOAC) in the last 5 years. They show a slightly improved effectiveness and a significantly improved safety profile compared with vitamin $\mathrm{K}$ antagonists, particularly with regard to bleeding [26-30].

Thus, systematically undetected AF is a systematic risk for stroke for patients who could otherwise benefit from an anticoagulation therapy. Therefore, early detection and appropriate measurements reduce the number and burden of strokes.
"Preventicus Heartbeats" is a Class 2a medical app with the purpose to detect and record the presence or absence of AF episodes by means of regular short measurements on the participant's mobile phone. The technology is based on recordings of photopethysmographic (PPG) signals which is widespreadly used for pulse detection. By simply putting a finger on the smartphone camera the pulse curve is recorded and automatically analysed. Pathological reports are reviewed by a telecare centre before indicating the result to the user. A training programme on how to perform measurements is integrated in the app as well as aids and feedback tools. Sensitivity and specifity of atrial fibrillation detection compared to the gold standard electrocardiogram were determined in prospective validation studies [31, 32]. Participants diagnosed with absolute arrhythmia during the "AF screening" will undergo a validation phase of up to 2 weeks. A continuously recording, telemetric chest ECG event recorder ("AF confirmation") allows the final diagnosis and an appropriate treatment of $\mathrm{AF}$ according to the guidelines, by ruling out incorrect screening results or results that are not relevant for treatment, which may arise from short-term arrhythmia episodes during the mobile phone measurement.

\section{Methods}

To assess the cost-effectiveness, we employed a model to compare the use of the "Preventicus Heartbeats" screening with a scenario without screening. Financial effects of the German morbidity-oriented risk structure compensation scheme (RSC) were optionally included. The course of the health state of the screening cohort was modelled based on parameters from official statistics and publications about topics "stroke", "atrial fibrillation and stroke" and "share of undetected atrial fibrillation".

The model is firstly constructed as long-term health history of a screening cohort over several periods for the remaining lifetime of the single participants. A Markov model was implemented, calculating specific states at any given point in time corresponding to different degrees of health or illness, see Fig. 1.

Depending on the events in a defined period (e.g. bleeding, stroke, death), the health state changes in the next period. This approach is a standard tool for the assessment of long-term cost-effectiveness (see [33], p. 295 et seq [34]).

Transition probabilities were defined for the transition between the health states, in which further information is included, depending on the previous health state. Age, gender, the presence of $\mathrm{AF}$, treatment with oral anticoagulants and previous strokes or cerebral haemorrhages were incorporated. 


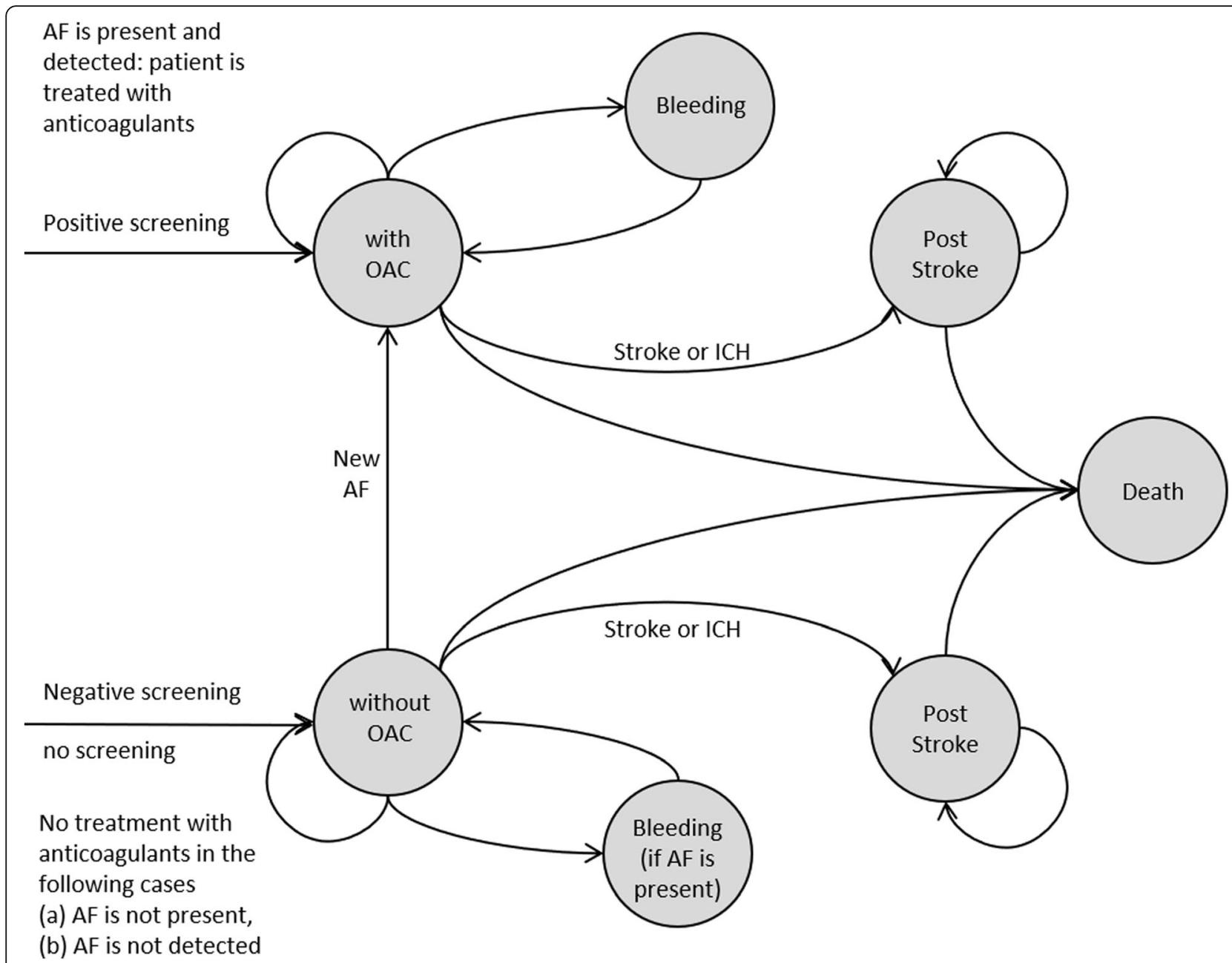

Fig. 1 Markov model structure

In the scenario with screening, the presence or absence of AF and the quality of the screening (sensitivity and specificity of the procedure) influence the transition probabilities. In the scenario without screening, a distinction is made between presence or absence of AF. For each of the observed cases a submodel with the different transition probabilities was constructed. The design of the model is a cohort model. The cohort is homogeneous in terms of starting age and gender.

Included are the costs of screening and the cost of anticoagulation among participants with newly detected $\mathrm{AF}$ and participants in whom AF was detected during the relevant time period without prior screening. During the further course of the model, the participants may suffer a stroke, cerebral haemorrhages or bleeding in other locations. The costs of these events are also included in the financial endpoint.

For additionally identified AF patients who are receiving anticoagulation treatment statutory sick funds are compensated according to the morbidity-oriented risk structure compensation scheme (RSC) if this is documented in two subsequent quarters. Similarly, strokes and cerebral haemorrhages also are compensated by RSC compensation if the patients are treated in hospital.

\section{Base case analysis}

Effectiveness of the screening is measured by the number of strokes prevented in participants with AF. For compatibility with the Scandinavian and AngloSaxon literature on the cost-effectiveness of screening measures, the effect of the screening measure is also calculated on the quality-adjusted life years (QALY) (for the QALY concept see [35]). Endpoints were calculated for a specified starting age and alternatively for men and women. The default starting age was set 75 years old in the base case, analogous to the Swedish model based on the "Strokestop" study [36]. The screening cohort in "Strokestop" was composed of 
insured persons (a) between the ages of 65 and 85 or (b) between the ages of 55 and 65, but who are at increased risk of AF or stroke due to underlying diseases such as high blood pressure or diabetes. The base case was calculated separately for men and women for all starting ages between 65 and 85 . The events were weighted by age and gender with fictitious shares in a screening population, which included the demographic population shares. It was also assumed that the participation rate will increase up to the age of 75 and then fall (see Fig. 2). The events were weighted by age and gender with fictitious shares in a screening population, which included the demographic population shares. It was also assumed that the participation rate will increase up to the age of 75 and then fall.

In order to gain insights into the effects of the screening for an entire population, the Markov cohort model was run separately for 42 strata (men and women and all starting ages between 65 and 85 years). The strata results were then weighted by their proportions in the fictitious population.

Under the German provisions of special care (Art. 140a (2) SGB [German Social Act] V) the costeffectiveness of any measure must be tested after 4 years.

\section{Deterministic sensitivity analyses}

The model parameters were subjected to a series of sensitivity analyses. Here, the base case model result (no deterioration of the result was shown when the RSC compensation payments were considered) proved to be robust against the changes in the parameters. Changes to the stroke rates and costs, the amounts of the RSC compensation payments, the starting age of the patients and the prevalence of undetected AF in the screening population had the strongest influence on the result of the model.

Sensitivity analyses are used to assess the dependency of the model results on certain assumptions and the stability of the model results. Nineteen model parameters were selected, which were expected to have a stronger impact on the model result, or which had no or only inaccurate prior information when selecting the parameters for the base case. Table 6 lists the parameters for the sensitivity analysis and the selected ranges of the parameters.

\section{Probabilistic sensitivity analysis}

While the deterministic sensitivity analysis only changes one parameter at a time and leaves the rest of the parameters unchanged, the probabilistic sensitivity analysis simultaneously changes a given set of parameters. For each of the varied parameters distribution assumptions are postulated, which either focus on the sampling error of the survey or represent further assumptions. For the analysis presented here, distribution assumptions were made for 32 parameters (see Appendix, Table 3). The distribution assumptions relate to transition probabilities, stroke costs and quality of life. This is based on the

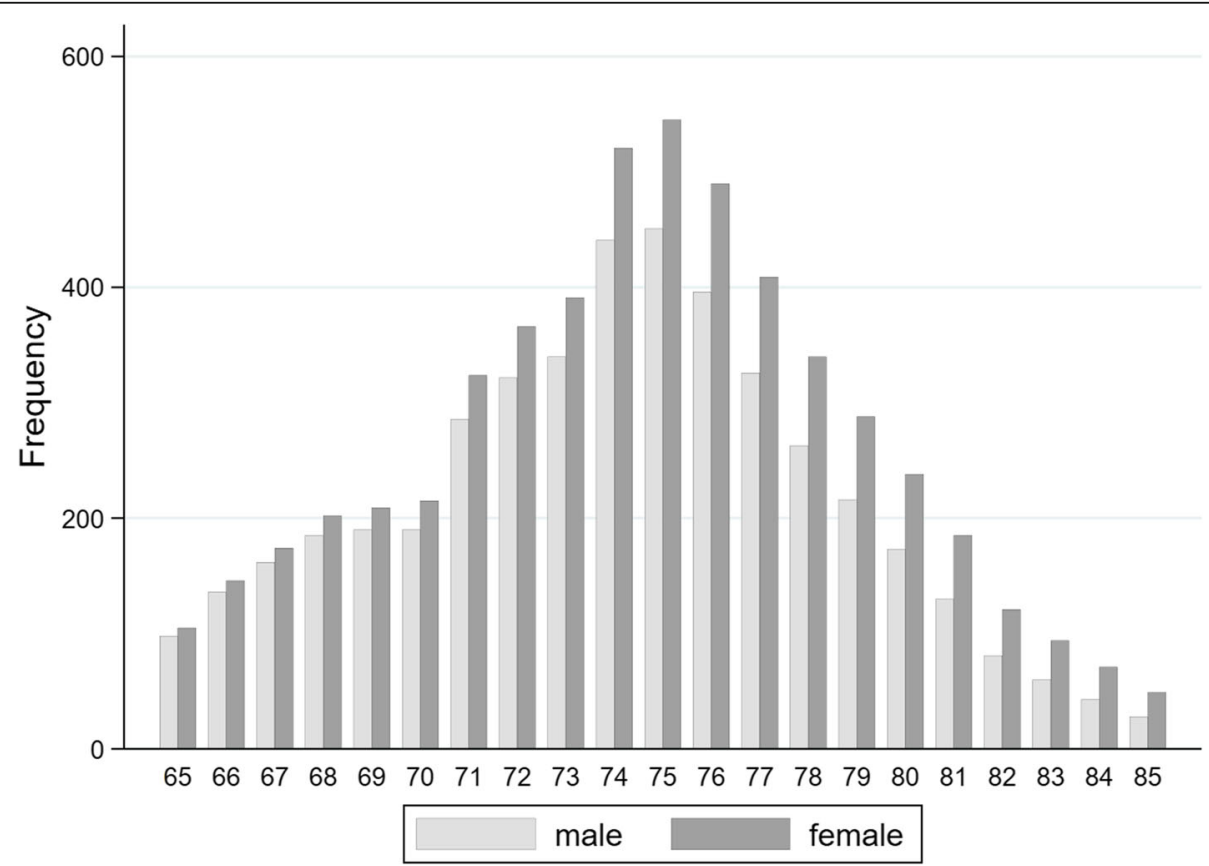

Fig. 2 Simulated population by age and gender 
simplistic assumption of independent distributions of the parameters.

In the probabilistic sensitivity analysis, the decision problem is considered from a Bayesian point of view. The a priori distributions of the parameters are linked to the empirical distributions of the observed populations using a Monte Carlo simulation. The result is an approximate value for the a posteriori distribution of the expected values. What is presented is the result of 1000 random selections from the distributions of the $32 \mathrm{pa}-$ rameters considered to be random.

A detailed description of the model parameters used in the base case and the sensitivity analyses is given in the Appendix.

\section{Software}

TreeAge Pro ${ }^{\circ}$, version 2019.2.1 was used to create and to calculate the model, including the probabilistic sensitivity analyses and the positioning of the observed alternatives about their incremental cost-effectiveness.

\section{Results}

\section{Base case}

\section{Timeframe: remaining lifetime}

The cohort with offer to participate in "Preventicus Heartbeats" screening showed cost advantage for both men and women. The cost advantage initially increases with the starting age up to a maximum, 77 years for men and 80 years for women. A higher cost advantage is found for men, due to the higher prevalence and incidence of stroke (see Fig. 3).
Including the compensation by the risk structure compensation scheme (RSC), the entire cohort outlined in Fig. 2 results in a cost advantage of $€ 109.96$ per included insured person for the "Preventicus Heartbeats" screening. This effect is approx. €35 higher in men (with $€ 128.80)$ than in women (€94.43).

\section{QALY delta}

For all subgroups observed, there is a slight increase in quality-adjusted life years. The QALY effect is correlated to starting age: men: 65 years old: + 0.008 QALY, 75 years old: + 0.018 QALY, 85 years old: + 0.021 QALY. In average the screening cohort gains +0.015 QALYs over remaining lifetime.

\section{Strokes prevented}

The AF screening prevents 54 cases of stroke in a screening population of 10,000 participants, men: 61 ; women: 48. Initial and subsequent events were included in the calculation. At a starting age of 75 (based on 10, 000 participants) 60 (men: 67, women: 55) strokes were prevented.

\section{Timeframe: four-year period}

Across the screening cohort outlined in Fig. 2, there is a cost advantage of $€ 23.59$ in favour of the "Preventicus Heartbeats" screening, including the compensation by the risk structure compensation scheme (RSC). This effect is approx. $€ 23$ higher in men (with €36.13) than in women $(€ 13.25)$.

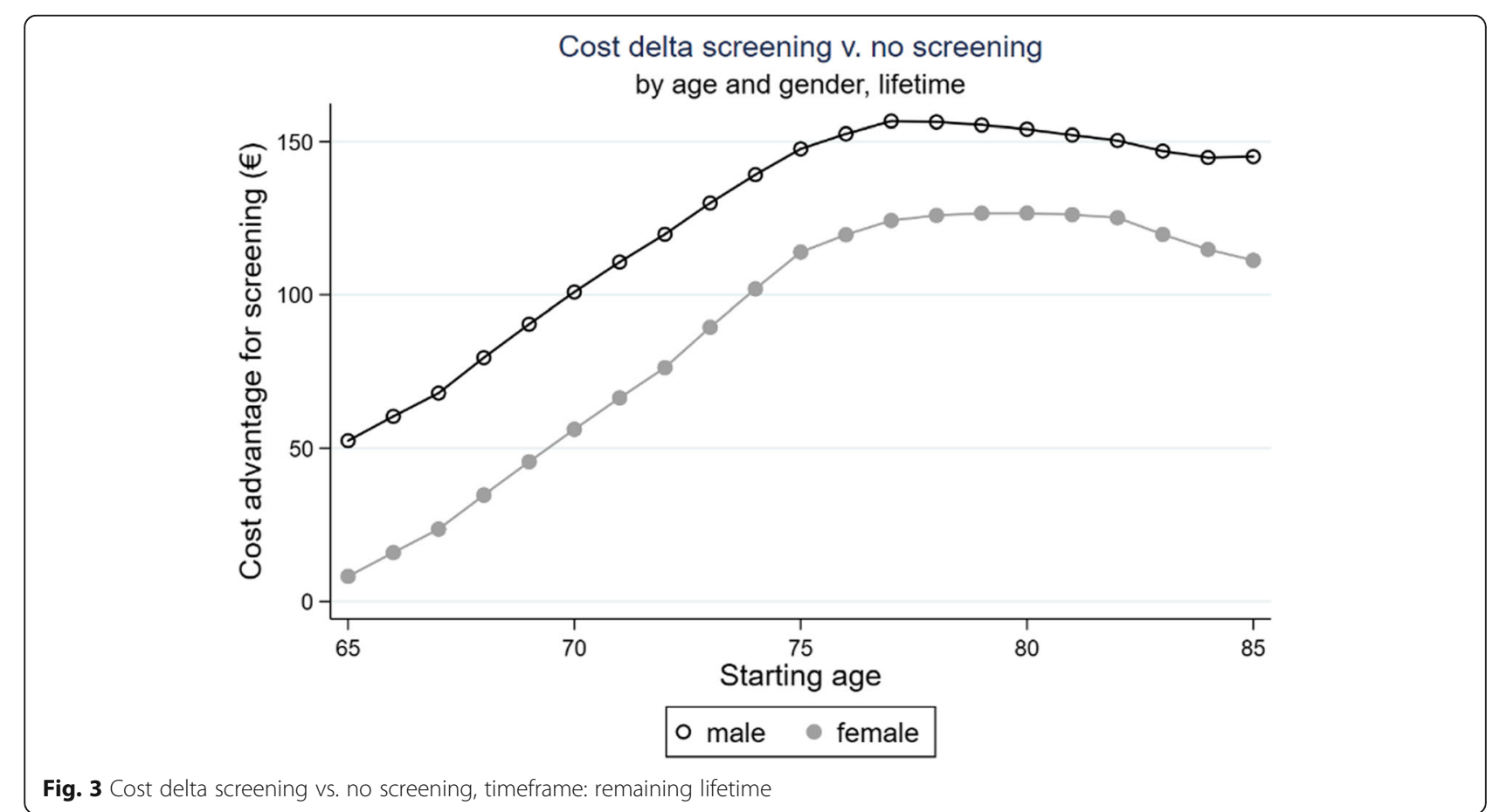




\section{Cost delta screening v. no screening}

by age and gender, 4 years after start

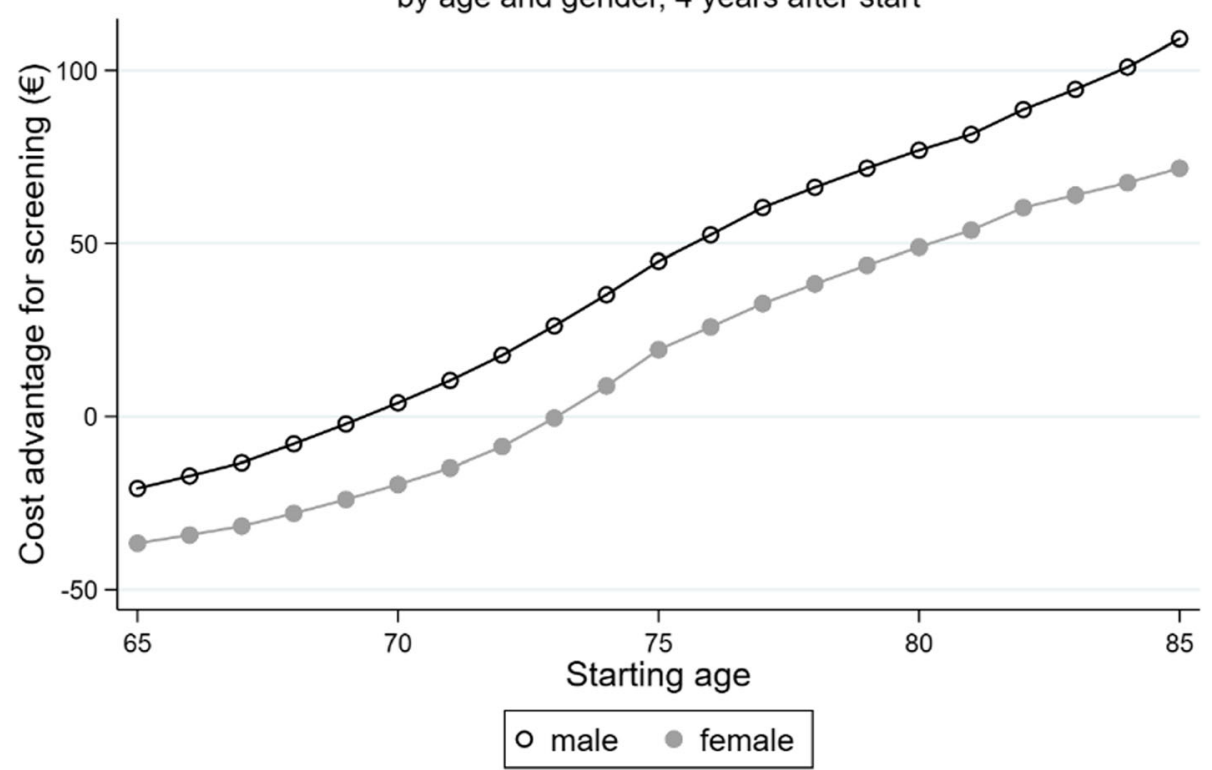

Fig. 4 Cost delta screening vs. no screening, timeframe: 4 years after screening

Participants with a relatively low starting age (men: up to 69 years old, women: up to 73 years old) do not achieve a cost advantage (see Fig. 4).

\section{QALY delta}

Over the next 4 years after the start of the project, quality-adjusted life years increased by 0.002 QALY.

\section{Strokes prevented}

Based on the first 4 years after the screening, AF screening prevents on average 24 cases of stroke in a screening population of 10,000 participants (men: 30; women: 20). Initial and subsequent events were included in the calculation. In the shorter timeframe, at a starting age of 75 years old (based on 10,000 participants), 27 (men: 32, women: 23) strokes were prevented.

\section{Tornado Diagram - Incremental Cost PrevCheck vs. No Test}

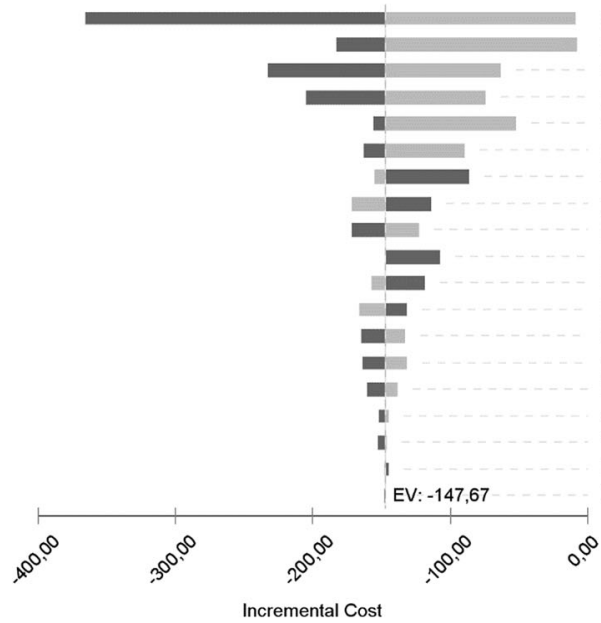

Undetected AF in \% detected AF $(0,7$ to 0,1$)$

Scaling factor for risk compensation (RSC) $(1,25$ to 0$)$ Scaling factor for stroke costs $(1,5$ to 0,5$)$

Effectiveness of stroke prevention $(0,9$ to 0,4$)$

Starting age ( 85 to 65$)$

Increased stroke rate with AF without prevention (5 to 2 )

Scaling factor for screening costs $(0,5$ to 5$)$

Increased background mortality, AF population ( 0 to 0,75 )

Positively validated screening results (by Holter ECG) $(0,95$ to 0,75$)$

Increased incidence of AF, AF population (1 to 3 )

Prices OAC after patent expires (actual: $100 \%)(0,4$ to 1$)$

Discount rate for costs $(0,01$ to 0,05$)$

Sensitivity Preventicus screening $(1$ to 0,85$)$

Marcumar proportion in OAC medication $(0,5$ to 0,1$)$

Rebate granted to health insurers $(0,25$ to 0$)$

Scaling factor costs cerebral haemorrhage $(3$ to 0,75$)$

Years until patent expiry (10 to 2)

Reduction in cerebral haemorrhage through NOAC $(0,35$ to 0,55$)$

Increase in the incidence of cerebral haemorrhage through VKA (10 to 3$)$

Incremental Cost

Fig. 5 Tornado chart: effect of the isolated parameter changes of 19 model parameters on the model result (each ceteris paribus), timeframe remaining lifetime, men; base case: starting age 75 years old 
Table 1 Results of the sensitivity analysis for 9 parameters with a high degree of fluctuation and the discount factor, timeframe remaining lifetime, starting age 75 years old

\begin{tabular}{|c|c|c|c|c|c|c|}
\hline Parameter & Variable & & $\begin{array}{l}\text { Minimum } \\
\text { value }\end{array}$ & $\begin{array}{l}\text { Delta } \\
\text { costs * }\end{array}$ & $\begin{array}{l}\text { Maximum } \\
\text { value }\end{array}$ & $\begin{array}{l}\text { Delta } \\
\text { costs a }\end{array}$ \\
\hline \multicolumn{2}{|c|}{$\begin{array}{l}\text { Base case, model timefram lifetime, starting age } 75 \text { years } \\
\text { Discounted by } 3 \%\end{array}$} & $\begin{array}{l}M \\
F\end{array}$ & & $\begin{array}{l}147.67 € \\
113.93 €\end{array}$ & & \\
\hline pAF & $\begin{array}{l}\text { Undetected AF in } \% \text { of detected AF } \\
\text { population (base case: } 33 \% \text { ) }\end{array}$ & $\begin{array}{l}\text { M } \\
F\end{array}$ & $10 \%$ & $\begin{array}{l}8.94 € \\
-1.18 €\end{array}$ & $70 \%$ & $\begin{array}{l}365.67 € \\
294.82 €\end{array}$ \\
\hline $\begin{array}{l}\text { cStroke_ } \\
\text { Factor }\end{array}$ & $\begin{array}{l}\text { Scaling factor stroke costs } \\
100 \%=\text { base case }\end{array}$ & $\begin{array}{l}\text { M } \\
F\end{array}$ & $50 \%$ & $\begin{array}{l}63.18 € \\
43.66 €\end{array}$ & $150 \%$ & $\begin{array}{l}232.15 € \\
184.20 €\end{array}$ \\
\hline RSA_Factor & Scaling factor RSA compensation payments; base case: factor 1.0 & $\begin{array}{l}M \\
F\end{array}$ & 0.0 & $\begin{array}{l}7.77 € \\
1,99 €\end{array}$ & 1.25 & $\begin{array}{l}182.64 € \\
141.91 €\end{array}$ \\
\hline $\begin{array}{l}\text { orStroke_AF} \\
\text { reduction }\end{array}$ & $\begin{array}{l}\text { Effectiveness of stroke prevention } \\
0 \% \text { - no effect; base case: } 70 \%\end{array}$ & $\begin{array}{l}M \\
F\end{array}$ & $40 \%$ & $\begin{array}{l}74.20 € \\
52.11 €\end{array}$ & $90 \%$ & $\begin{array}{l}204.81 € \\
161.76 €\end{array}$ \\
\hline AgeStart & $\begin{array}{l}\text { Starting age of the population } \\
\text { Base case: } 75 \text { years old }\end{array}$ & $\begin{array}{l}M \\
F\end{array}$ & 65 years old & $\begin{array}{l}52.42 € \\
8.22 €\end{array}$ & 85 years old & $\begin{array}{l}156.65 € \\
126.67 €\end{array}$ \\
\hline $\begin{array}{l}\text { orStroke_AF_ } \\
\text { NOATT }\end{array}$ & Increased stroke rate with AF without prevention; Base case: factor 4.2 & $\begin{array}{l}M \\
F\end{array}$ & 2.0 & $\begin{array}{l}89.75 € \\
64.33 €\end{array}$ & 5.0 & $\begin{array}{l}163.29 € \\
127.32 €\end{array}$ \\
\hline cTest_Factor & $\begin{array}{l}\text { Scaling factor screening costs } \\
100 \%=\text { base case }(€ 47.54 / € 297.50)\end{array}$ & $\begin{array}{l}M \\
F\end{array}$ & $50 \%$ & $\begin{array}{l}155.34 € \\
119.88 €\end{array}$ & $500 \%$ & $\begin{array}{l}86.27 € \\
66.28 €\end{array}$ \\
\hline orMortAF_base & $\begin{array}{l}\text { Increased background mortality, AF subpop. } \\
25 \% \text { increase = base case }\end{array}$ & MF & $0 \%$ & $\begin{array}{l}171.69 € \\
131.13 €\end{array}$ & $75 \%$ & $\begin{array}{l}113.86 € \\
89.36 €\end{array}$ \\
\hline Discount rate & $\begin{array}{l}\text { Discount factor } \\
3 \%=\text { base case }\end{array}$ & $\begin{array}{l}M \\
F\end{array}$ & $1 \%$ & $\begin{array}{l}164.53 € \\
127.87 €\end{array}$ & $5 \%$ & $\begin{array}{l}132.34 € \\
101.26 €\end{array}$ \\
\hline
\end{tabular}

a Delta costs: cost advantage for screening strategy (if positive), cost disadvantage for screening strategy (if negative)

\section{Deterministic sensitivity analyses}

Timeframe remaining lifetime: A deterministic sensitivity analysis for all selected parameters is performed in a tornado chart. The parameters are then sorted according to the fluctuation range of the endpoint (here: cost impact of the screening taking into account the effects of RSA) and presented as a deviation from a reference line (here: "EV" = "expected value", corresponds to the base case result). In TreeAge Pro ${ }^{\bullet}$ the effects of decreased parameter values are shown in light shading and

\section{Tornado Diagram - Incremental Cost PrevCheck vs. No Test}

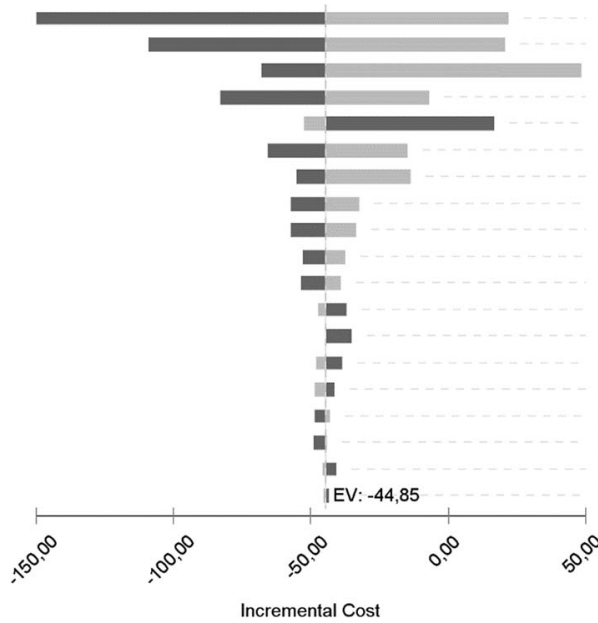

Undetected AF in \% detected AF $(0,7$ to 0,1$)$ Starting age ( 85 to 65$)$

Scaling factor for risk compensation (RSC) $(1,25$ to 0$)$

Scaling factor for stroke costs $(1,5$ to 0,5$)$

Scaling factor for screening costs $(0,5$ to 5$)$

Effectiveness of stroke prevention $(0,9$ to 0,4$)$

Increased stroke rate with AF without prevention (5 to 2$)$

Positively validated screening results (by Holter ECG) $(0,95$ to 0,75$)$

Marcumar proportion in OAC medication $(0,5$ to 0,1$)$

Sensitivity Preventicus screening $(1$ to 0,85$)$

Rebate granted to health insurers $(0,25$ to 0$)$

Prices OAC after patent expires (actual: $100 \%)(0,4$ to 1$)$

Increased incidence of $A F, A F$ population (1 to 3 )

Increased background mortality, AF population $(0$ to 0,75 )

Discount rate for costs $(0,01$ to 0,05$)$

Scaling factor costs cerebral haemorrhage $(3$ to 0,75$)$

Increase in the incidence of cerebral haemorrhage through VKA (10 to 3)

Years until patent expiry (2 to 10 )

Reduction in cerebral haemorrhage through NOAC $(0,35$ to 0,55$)$

Incremental Cost

Fig. 6 Tornado chart: effect of the isolated parameter changes of 19 model parameters on the model result (each ceteris paribus), timeframe: 4 years, men; base case: starting age 75 years old 
the effects of increased parameter values are shown in dark shading. Figure 5 shows the tornado chart for the timeframe "remaining lifetime" and for men with a starting age of 75 . The result for women only differs slightly (Table 1).

The model endpoint "Delta costs incl. RSA effect" is negative for all observed variants. Considering the effect of the RSA, it can be assumed that the screening has a positive earnings effect. The parameter "undetected AF in $\%$ of detected AF", for which a relatively wide parameter range of $10 \%$ to $70 \%$ is assumed, has the strongest impact on the change in costs (in 75-year-old men: - $€ 9$ with a share of $10 \%$ up to $-€ 366$ with a share of $70 \%$ undetected $\mathrm{AF}$ ).

The variation of influential factors linked to the frequency and costs of strokes also has a strong impact on the model result as well as the amount of the compensation payments from the RSA. In case of a complete cessation of the RSA, the model endpoint in the base case decreases from $€ 148$ to $€ 8$ for men and from $€ 114$ to $€ 2$ for women. Table 1 lists the results for 9 parameters with high fluctuation ranges.

\section{Timeframe four years}

Figure 6 shows the tornado chart for the timeframe 4 years for men with a starting age of 75 . Compared to the timeframe remaining lifetime, the starting age and the scaling factor RSA gain in importance. The complete cessation of the RSA would result in a negative cost delta of $€ 49$ for men and $€ 51$ for women. Negative earnings effects also arise if extreme changes occur in other parameters. One example is a strong reduction of the "prevalence parameter" (undetected AF in \% of detected AF) from 33 to $10 \%$ (see Table 2). As a result of the shorter timeframe, the effect of the discount factor is reduced. The parameter "undetected AF in \% of detected $\mathrm{AF}^{\prime \prime}$ and the parameters linked to the frequency and the costs of a stroke, have a strong impact on the model result, even in the shorter timeframe.

Table 2 lists the results for nine parameters with a high degree of variation that appear in the shorter timeframe.

\section{Probabilistic sensitivity analysis (PSA) Cost delta}

The distribution of expected cost changes (including the RSA effect) is shown in Fig. 7 (a). The simulation shows the distribution for men, a timeframe lifetime and a starting age of 75 . The values are scattered around an average value of $-€ 109$ (Base Case: $-€ 147.67$ ) with a standard deviation of $€ 41$. No cost increases were observed in any of the 1000 simulations. The values are scattered between $-€ 258$ (best value) and $-€ 6$ (worst value). With a $95 \%$ probability, the endpoint is situated between $-€ 189$ and $-€ 29$.

For a timeframe of 4 years, the distribution moves to the right. The distribution of the endpoint "Expected cost change" (including the RSA effect) is shown in Fig. 7 (b).

Table 2 Results of the sensitivity analysis for 9 parameters with a high degree of fluctuation and the discount factor, timeframe four years, starting age 75 years old

\begin{tabular}{|c|c|c|c|c|c|c|}
\hline Parameter & Variable & & $\begin{array}{l}\text { Minimum } \\
\text { value }\end{array}$ & $\begin{array}{l}\text { Delta } \\
\text { costs }^{\text {a }}\end{array}$ & $\begin{array}{l}\text { Maximum } \\
\text { value }\end{array}$ & $\begin{array}{l}\text { Delta } \\
\text { Costs }\end{array}$ \\
\hline \multicolumn{2}{|c|}{$\begin{array}{l}\text { Base case, model timeframe } 4 \text { years, starting age } 75 \text { years } \\
\text { Discounted by } 3 \%\end{array}$} & $\begin{array}{l}M \\
F\end{array}$ & & $\begin{array}{l}44.85 € \\
19.31 €\end{array}$ & & \\
\hline pAF & $\begin{array}{l}\text { Undetected AF in \% of detected AF } \\
\text { population (base case: } 33 \% \text { ) }\end{array}$ & $\begin{array}{l}M \\
F\end{array}$ & $10 \%$ & $\begin{array}{l}-21.91 € \\
-29.57 €\end{array}$ & $70 \%$ & $\begin{array}{l}149.75 € \\
96.13 €\end{array}$ \\
\hline $\begin{array}{l}\text { cStroke_- } \\
\text { Factor }\end{array}$ & $\begin{array}{l}\text { Scaling factor stroke costs } \\
100 \%=\text { base case }\end{array}$ & $\begin{array}{l}M \\
F\end{array}$ & $50 \%$ & $\begin{array}{l}6.85 € \\
-7.94 €\end{array}$ & $150 \%$ & $\begin{array}{l}82.84 € \\
46.57 €\end{array}$ \\
\hline RSA_Factor & Scaling factor RSA compensation payments; base case: factor 1.0 & $\begin{array}{l}M \\
F\end{array}$ & 0.0 & $\begin{array}{l}-48.57 € \\
-50.53 €\end{array}$ & 1.25 & $\begin{array}{l}68.20 € \\
36.77 €\end{array}$ \\
\hline $\begin{array}{l}\text { orStroke_AF_- } \\
\text { reduction }\end{array}$ & $\begin{array}{l}\text { Effectiveness of stroke prevention } \\
0 \% \text { - no effect; base case: } 70 \%\end{array}$ & $\begin{array}{l}M \\
F\end{array}$ & $40 \%$ & $\begin{array}{l}14.87 € \\
-2.51 €\end{array}$ & $90 \%$ & $\begin{array}{l}65.86 € \\
34.58 €\end{array}$ \\
\hline AgeStart & $\begin{array}{l}\text { Starting age of the population } \\
\text { Base case: } 75 \text { years old }\end{array}$ & $\begin{array}{l}M \\
F\end{array}$ & 65 years old & $\begin{array}{l}-20.72 € \\
-36.56 €\end{array}$ & 85 years old & $\begin{array}{l}109.05 € \\
71.69 €\end{array}$ \\
\hline $\begin{array}{l}\text { orStroke_AF_- } \\
\text { NOATT }\end{array}$ & Increased stroke rate with AF without prevention; Base case: factor 4.2 & $\begin{array}{l}M \\
F\end{array}$ & 2.0 & $\begin{array}{l}13.81 € \\
-3.48 €\end{array}$ & 5.0 & $\begin{array}{l}55.05 € \\
26.85 €\end{array}$ \\
\hline cTest_Factor & $\begin{array}{l}\text { Scaling factor screening costs } \\
100 \%=\text { base case }(€ 47.54 / € 297.50)\end{array}$ & $\begin{array}{l}M \\
F\end{array}$ & $50 \%$ & $\begin{array}{l}52.52 € \\
25.27 €\end{array}$ & $500 \%$ & $\begin{array}{l}-16.55 € \\
-28.33 €\end{array}$ \\
\hline orMortAF_base & $\begin{array}{l}\text { Increased background mortality, AF subpop. } \\
25 \% \text { increase = base case }\end{array}$ & $\begin{array}{l}M \\
F\end{array}$ & $0 \%$ & $\begin{array}{l}48.17 € \\
20.99 €\end{array}$ & $75 \%$ & $\begin{array}{l}38.77 € \\
16.19 €\end{array}$ \\
\hline Discount rate & $\begin{array}{l}\text { Discount factor } \\
3 \%=\text { base case }\end{array}$ & $\begin{array}{l}M \\
F\end{array}$ & $1 \%$ & $\begin{array}{l}48.42 € \\
21.99 €\end{array}$ & $5 \%$ & $\begin{array}{l}41.51 € \\
16.82 €\end{array}$ \\
\hline
\end{tabular}

a Delta costs: cost advantage for screening strategy (if positive), cost disadvantage for screening strategy (if negative) 

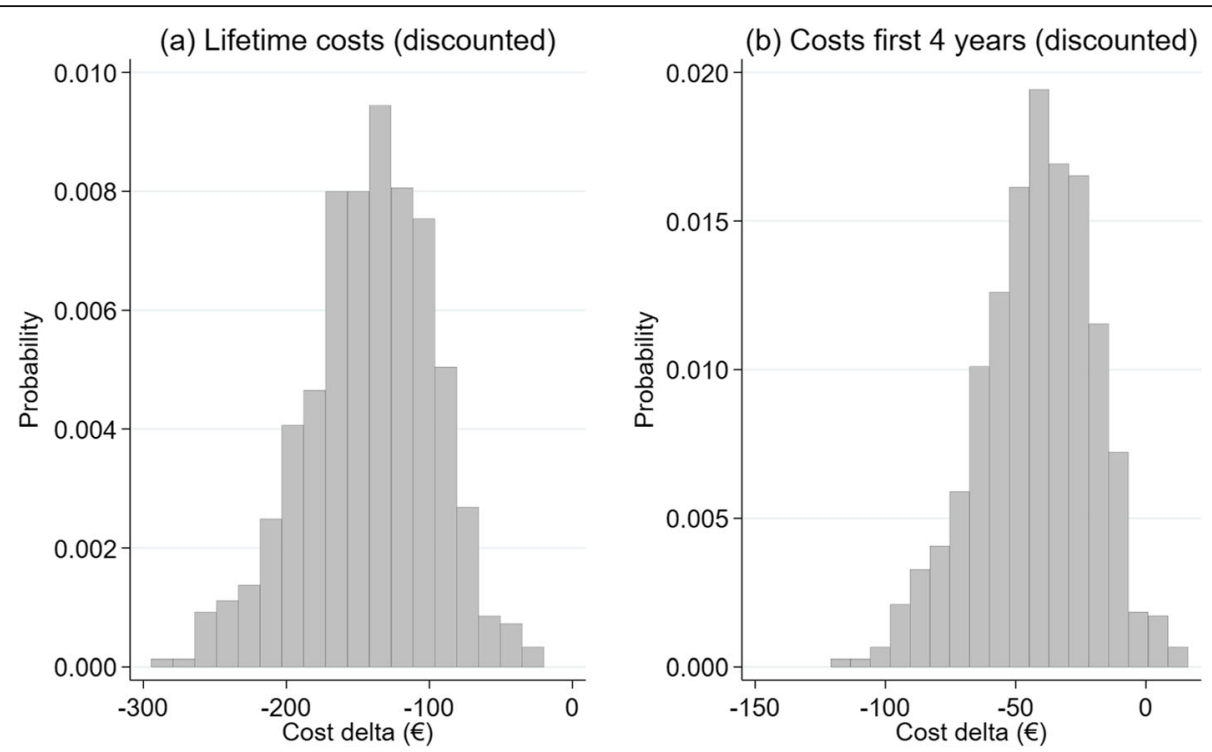

Fig. 7 Result of the probabilistic sensitivity analysis: expected change in the result (Delta costs including RSA effect), timeframe lifetime (a), 4 years (b), men, base case: starting age 75 years old

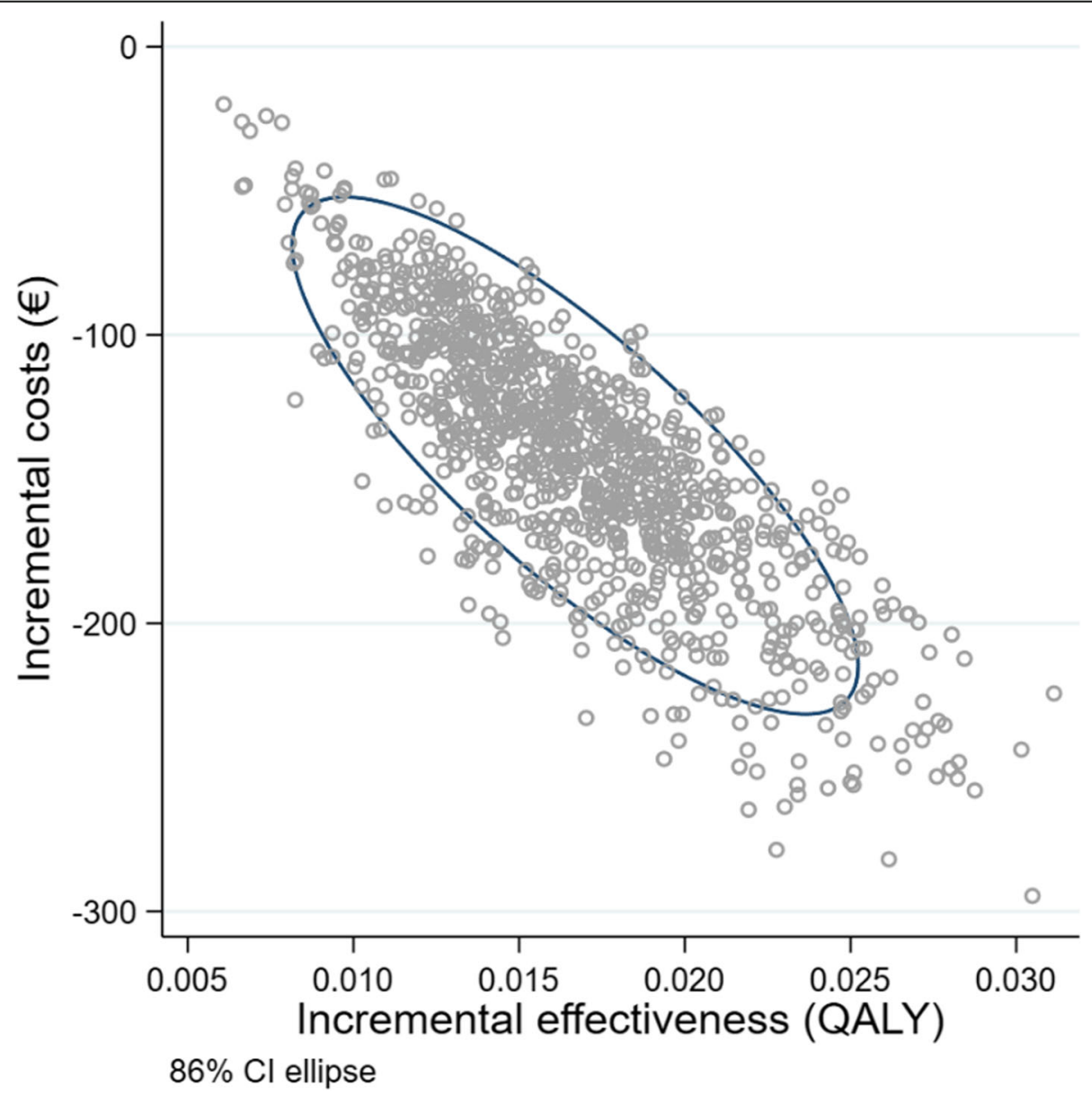

Fig. 8 Result of the probabilistic sensitivity analysis: incremental cost-effectiveness and 95\% confidence ellipse, timeframe lifetime, men; base case: starting age 75 years old 
The values are scattered around an average value of $-€ 45$ (base case: -€44.85) with a standard deviation of $€ 21.7$. The values are scattered between - $€ 132$ (best value) and + $€ 24.5$ (worst value). With a 95\% probability, the endpoint is situated between - $€ 91$ and $-€ 6$.

\section{Incremental cost-effectiveness analysis (ICER)}

The result of the screening shows a slight increase of the quality-adjusted life years from 7.907 to 7.923 years (standard deviation 0.08 QALY) for men with a starting age of 75 and the timeframe remaining lifetime, whereby the costs have also decreased (taking into account the RSA effect). This means that, when it comes to choosing between the alternatives "Preventicus Heartbeats screening" and "no screening", the alternative "Preventicus Heartbeats screening" is dominant (i.e. has a higher effectiveness with less costs). The result of the Incremental Cost-Effectiveness Analysis for men, starting age of 75, is shown as a two-dimensional ICER graph in Fig. 8.

The result for women, starting age 75 years old, corresponds to the result for men. The costs have decreased, and the number of quality-adjusted life years rises from 9.258 to 9.273 years (standard deviation 0.07 QALY).

\section{Discussion}

The present model shows the cost-effectiveness of a systematic screening procedure for a population compared to the alternative (no screening). Although the screening goes hand in hand with higher costs for stroke prevention, the costs are already offset in the short term by the lower costs for acute treatment and follow-up treatment, which result from the lower number of strokes. Added to this are compensation amounts from the morbidity-oriented risk structure compensation scheme, which lead to a positive change to the results because of the screening.

Central cost data, such as the treatment costs for a stroke, were compiled from German sources. This is also the case for the incidence and prevalence data used and the restrictions for the mortality rates.

The literature lists a series of other cost-effectiveness models to assess procedures to detect previously undetected atrial fibrillation using a screening procedure. A systematic literature review and a model on the topic from a health economics point of view were carried out by [37] as part of a Health Technology Assessment for the NICE Institute. Another model of note is a costeffectiveness model by the HIQA Institute in Ireland [38] as part of an HTA, which was also based on Irish healthcare information. The comprehensive model as part of the NICE-HTA showed an average approval rate ("uptake ratio") of $64 \%$. The average proportion of previously undiagnosed AF among the screening participants was $35 \%$. Overall, systematic opportunistic strategies performed better than the systematic screening of entire populations and the cost-effectiveness increases with an increasing starting age ([37], Table 47).

With regard to the implementation of the screening, the Swedish "Strokestop" study [15] was found to be very similar to the "Preventicus Heartbeats" screening [36]. carried out a cost-effectiveness analysis based on the results and methods of the "Strokestop" study. At an increased cost of $€ 50$ per participant, the study showed an increase of the quality-adjusted life years from 6.646 to 6.657 QALY and an ICER ratio of $€ 4313$ per additional QALY. Compared to the reference scenario (Standard Care), eight cases of stroke were prevented among 1000 screening participants during the remaining lifetime of the simulated subjects.

For Switzerland, the cost effectiveness for the use of anticoagulant therapy was estimated between CHF 9702 and CHF 25,108 for the gain of a QALY [39].

The result of the studies mentioned is a cost increase due to the screening measures, which is accompanied, however, by an increase in effectiveness.

The presented cost-effectiveness model, on the other hand, showed a decrease in costs for almost all observed scenarios, accompanied by an increase in effectiveness. This effect is even greater because of the RSC compensation payments, which are not included in foreign studies, but which fully impact the results and premiums for statutory healthcare insurers in Germany.

A major difference compared to the "Strokestop" model [37] is the low screening costs (for the "Preventicus Heartbeats" scenario $€ 47.54$ for the app incl. Quality assurance and the examination of obvious defects in case of conspicuous results and $€ 297.50$ for the validation by means of a 14-day ECG), which only apply in case of positive and quality-tested app results [36]. lists costs of $€ 108$ for registration and ECG measurement in the 1st phase. In the second phase, the costs are $€ 266$ for a 24-h ECG.

The increased stroke rate in the presence of AF without prevention is three times the rate of that with prevention, according to [36], whereas it is four times the rate in this model and in the Framingham study [38, 40]. shows an age-dependency of the relative risk of stroke associated with AF in the Framingham data (Fig. 5.8). A scenario with threefold increased stroke risk was tested in our sensitivity analyses, without changing the basic statement of the present model.

As is the case in other studies (such as the Irish HTA by [36, 38] assume lower stroke costs. Aronsson et.al. [36] cite a Swedish study on stroke costs, which yielded $€ 18,175$ for the first year after the acute event and $€ 4336$ as costs for subsequent years. The $50 \%$ reduction in the costs of a stroke shown by this model $(€ 21,060$ in the first year and $€ 6231$ in subsequent 
years) were also tested in a sensitivity analysis (see Tables 1 and 2).

The differences between the design of the model used in this study and other cost-effectiveness models offer starting points for optional further development. The presented model regards age and gender as significant influential factors for the incidence rates [36], for example, use the $\mathrm{CHA}_{2} \mathrm{DS}_{2}$ VASC score of the 1000 simulated participants of the Strokestop study. The Markov model in the NICE-HTA [37] includes health states which summarise different previous events (e.g. bleedings and strokes). This model only assigns the simulated subjects one health state each at any given point in time. Also different from other studies is the number of simulated phases per year in the remaining lifetime. The length of the phases in this study is 1 year, whereas other studies include several multi-year phases.

A starting age of under 65 years is not included in the model. If the participant cohort is limited to individuals with an increased $\mathrm{CHA}_{2} \mathrm{DS}_{2}$ VASC score, an improved model result can also be expected for younger participants. To quantify this effect, this model approach should be expanded by including the $\mathrm{CHA}_{2} \mathrm{DS}_{2}$ VASC score, which can be based on study results for younger arrhythmia patients and their risk factors, insofar as these are available. From the viewpoint from comparing the reliability to the simulation results, the future study had better take a heterogeneous population like Herman et al. [41] into account.

\section{Conclusions}

The present study shows the positive effect on the results and premiums of a systematic screening by means of the Preventicus screening procedure using population and cost information which is relevant for the implementation of the screening procedure in Germany.

\section{Appendix: Model parameters}

Share of undetected AF in the screening population: The model assumption based on the findings of the "Strokestop" study [15] and a systematic review [42]. In the base case, it is assumed that the proportion of participants with undetected AF is $33 \%$ of the prevalence of known AF in the screening population. The AF prevalence values are based on the findings of a study by [43] that analysed data from Barmer GEK [German health insurer]. The percentage of participants with undetected $\mathrm{AF}$ is linked to the prevalence of $\mathrm{AF}$ and therefore dependent on the starting age and gender of the screening cohort.

Sensitivity and specificity of the "Preventicus Heartbeats" screening. The values (sensitivity: 91.5\%, specificity: 99.6\%) are based on [31]'s study. It is assumed that
85\% of cases detected by the "Preventicus Heartbeats" screening are confirmed with a Holter ECG in the twoweek validation period [44].

Starting age of the cohort: Analogous to the "Strokestop" study, a starting age of 75 was chosen in the Base Case. Gender and starting age were provided for a simulated cohort. General ("background") mortality was chosen from the German mortality tables [45]). The stroke mortality was deduced from the background mortality based on standardised mortality rates [46].

Incidence and prevalence: The following incidence and prevalence rates are dependent on age and gender:

- Incidence and prevalence of atrial fibrillation [43] with an impact on the prevalence of undetected AF in the screening population

- Incidence of ischaemic strokes ([3], published in age ranges of 10 years, exponentially interpolated)

- Incidence of intracranial haemorrhages ([47], published in age ranges of 20 years, exponentially interpolated).

The incidence rates for $\mathrm{AF}$, stroke and intracranial haemorrhage are based on normal populations. For patients who suffer from AF and in case of prevention with anticoagulants, the incidence and prevalence rates are higher.

The transition probabilities are essentially based on the table values for mortality and incidence and are therefore age- and gender-dependent. For some parameters (e.g. haemorrhages) probabilities are chosen that are independent of age and gender. The following events can be distinguished: Stroke, intracranial haemorrhage, other bleeding and mortality. Age- and gender dependent parameter values are listed in Table 4.

Stroke: Assumptions are based on the publication by [3]. The probability depends on the fact whether AF is present and - if so - whether there is stroke prevention:

- $\mathrm{AF}$ is not present: use of interpolated original values (factor 1)

- $\mathrm{AF}$ is present, no stroke prevention with OAC: the original values are multiplied by a factor of 4.2 (result of the Framingham Study, [40]). To prevent calculated probabilities greater than 1 , the factor is interpreted as an odds ratio.

- $\mathrm{AF}$ is present, stroke prevention with OAC: according to studies on the effectiveness of vitamin $\mathrm{K}$ antagonists and the new oral anticoagulants. Meta analyses comparing Warfarin against Placebo [23] and Warfarin against direct OAC [26] suggest a total stroke reduction of 70 to $80 \%$. We assume a decrease of around $70 \%$ compared to cases without prevention with OAC. 
- For the subsequent years after the initial stroke, a recurrence rate of $12 \%$ p.a. is assumed for a new stroke. This number is based on the results of [48] and [49], who obtained a five-year recurrence rate of $24 \%$ for the Erlangen register.

Intracranial haemorrhage (ICH): The probability is based on the statistics of [47]. If AF is present, this is adjusted. This is also the case for prevention with OAC.

- $\mathrm{AF}$ is not present: use of the original values of [47].

- $\mathrm{AF}$ is present, no stroke prevention with OAC: Multiplication of the original values by factor 4 . The assumption is based on the increased number of ICH, reported by a Swedish cohort study [50].

- $\mathrm{AF}$ is present, stroke prevention with OAC: in cases treated with vitamin $\mathrm{K}$ antagonists, no further increase is assumed compared to cases without prevention. If treated with $\mathrm{NOAC}$, the probability of suffering an intracranial haemorrhage is reduced by a factor of 0.41 . This is based on the results of the NOAC-Warfarin-comparisons included in the metaanalysis by [51].

Other bleeding: Under certain conditions, atrial fibrillation is linked to other types of bleeding. The model distinguishes:

- Severe bleeding (“major bleedings", e.g. gastrointestinal bleeding). For participants with AF who do not receive stroke prevention, a probability of $2.3 \%$ is assumed (source [50], Table 6). This probability increases to $3.9 \%$ in cases of stroke prevention (value averaged from $5.2 \%$ in cases of prevention with vitamin $\mathrm{K}$ antagonists and $3.3 \%$ in cases of prevention with NOAC (source [29], Table 3 ). It could be considered that it is reported that some NOACs may increase gastrointestinal bleeding

- Less severe bleeding ("minor bleedings"): a study on the NOAC Dabigatran determined a 14\% probability for less severe bleeding in case of stroke prevention with Dabigatran ([29], Table 3). For the probability of less severe bleeding when AF is present with no stroke prevention, it is assumed that the value corresponds to approximately $6 / 10$ of the bleeding probability with OAC medication, as is the case with severe bleeding (result: assumption of 8.3\%). Once the bleeding has been treated, the OAC medication is continued in accordance with the $\mathrm{AF}$ guidelines [25].

Mortality. Following the results of Wolf [52] and Friberg [65], background mortality is adjusted for the subpopulation with AF. The increased mortality is partly due to the increased risk of stroke, but also due to other cardiovascular diseases like heart failure and ischaemic hart diseases ([65], Table 3). In the base case model, background mortality for the AF subpopulations will be increased by $25 \%$ (assumption, based on the differences in mortality occurrence shown by [52], Table 2).

A distinction is made between mortality with and without stroke:

- Mortality without stroke: this is represented in the mortality tables [45].

- Mortality after stroke: use of the "standardised mortality rates" of stroke patients, collected in Denmark [46]. A distinction is made between mortality in the first year after the stroke and in subsequent years.

- Mortality after a second stroke: increase of $50 \%$ over the "standardised mortality rates" after the initial stroke. The assumption is based on figures from the Perth register [48], which reported a $22 \%$ mortality rate for the first 28 days after the initial event and a $41 \%$ mortality rate after the subsequent event.

- Mortality after intracranial haemorrhage: $48.6 \%$; source [54], Fig. 1.

Later detection of AF: For participants with undetected AF or non-existing AF, the incidence figures collected from [43] were used as probabilities for the later detection or the spontaneous occurrence of atrial fibrillation. This is true for both the "Preventicus Heartbeats" scenario and the scenario without screening.

Stroke prevention with oral anticoagulants: All patients who were found to suffer from AF in the screening or at a later point in time received a treatment for stroke prevention. The following assumptions are made:

- The proportion of vitamin $\mathrm{K}$ antagonists (usually Phenprocoumon/Marcumar ${ }^{\circ}$ ) in the treatment is $29 \%$ (in the base case). This is an assumption, as no figures have been published on the use of oral anticoagulants for AF diagnosis in Germany. According to [66] (Central Illustration), a 37.8\% proportion of vitamin $\mathrm{K}$ antagonists was determined in the GLORIA-AF project. The lower value used in the model is based on the fact, among other things, that stroke prevention is no longer carried out with VKA but with NOAC for almost all new cases.

- The adherence to drug therapy is assumed to be initially $100 \%$. After the first year, $10 \%$ of patients stop the medication and in subsequent years $5 \%$ of the remaining patients given they have not changed to a different state of health. These changes are all based on assumptions. 
Table 3 PSA distributions and parameters, base case values

\begin{tabular}{|c|c|c|c|c|c|}
\hline Original name & Type & Param 1 & Param 2 & $\begin{array}{l}\text { Base } \\
\text { Case }\end{array}$ & Description \\
\hline \multicolumn{6}{|l|}{ General } \\
\hline Undetected AF in \% detected AF & Beta & 37.9 & 962.1 & 0.038 & $\begin{array}{l}\text { Assumption (prevention, } 1 / 3 \\
\text { ratio undetected AF to detected AF) }\end{array}$ \\
\hline Sensitivity Preventicus screening b & Beta & 229 & 21 & 0.92 & from DETECT AF [31] \\
\hline Specificity Preventicus screening ${ }^{b}$ & Beta & 342.624 & 1.376 & 0.99 & from DETECT AF [31] \\
\hline Positively validated screening results (after Holter ECG) ${ }^{b}$ & Beta & 9.9875 & 1.7625 & 0.85 & Adoption acc. to Wachter et.al [44]. \\
\hline \multicolumn{6}{|l|}{ Prevention } \\
\hline Marcumar proportion in OAC medication & Triangular & \multicolumn{2}{|c|}{$0.05 / 0.2 / 0.5$} & \multicolumn{2}{|l|}{0.29} \\
\hline Increased stroke rate with AF without prevention & Normal & 4.2 & 0.235 & 4.20 & mean: Wolf et.al [40]. SD: assumption \\
\hline Reduction of stroke rate through prevention ${ }^{b}$ & Normal & 0.686 & 0.05 & 0.70 & $\begin{array}{l}\text { Assumptions, based on Hart [23] and López- } \\
\text { López [26] }\end{array}$ \\
\hline \multicolumn{6}{|l|}{ Strokes and Mortality } \\
\hline Stroke rate normal population & Normal & 1.00 & 0.14 & 1.00 & SD according to Kolominisky-Rabas [49] \\
\hline Frequency of recurrent stroke & Beta & 52.48 & 275.52 & 0.160 & Hardie [48]: Perth registry \\
\hline Mortality, year $1(\mathrm{SMR})^{\mathrm{a}}$ & Normal & 3.7 & 0.3 & 3.7 & Bromum-Hansen [46], year 0-1 \\
\hline Mortality, subsequent years (SMR) ${ }^{a}$ & Normal & 1.92 & 0.13 & 1.92 & Bronnum-Hansen [46], years 2-5 \\
\hline Mortality, recurrence (SMR factor) & Triangular & \multicolumn{2}{|c|}{$1.0 / 1.5 / 2.0$} & 1.5 & Assumption according to Hardie [48] \\
\hline Stroke costs, year 1 & Gamma & 434.0277 & 0.02344 & 18,517 & $\begin{array}{l}\text { Kolominsky-Rabas [3] / variation } \\
\text { coefficient derived from lifetime, } \\
2006 \text { prices }\end{array}$ \\
\hline Stroke costs, subsequent years & Gamma & 434.0277 & 0.07922 & 5479 & discounted costs, 2006 prices \\
\hline Increased mortality, AF subpopulations & Normal & $25 \&$ & $5 \%$ & $25 \%$ & Wolf, Mitchel [52] \\
\hline \multicolumn{6}{|l|}{ Frequency of bleeding } \\
\hline Severe bleedings, without OAC: & Normal & 0.023 & 0.00153 & 0.023 & Friberg $[29,50]$, Granger: Apixaba n[29] \\
\hline Severe bleedings, with OAC & Normal & 0.039 & 0.0026 & 0.039 & Mix of VKA and NOAC \\
\hline Less severe bleedings, without OAC & Normal & 0.08256 & 0.00242 & 0.0823 & $\begin{array}{l}\text { Assumption: ratio with/without same as with } \\
\text { severe bleeding }\end{array}$ \\
\hline Less severe bleedings, with OAC & Normal & 0.14 & 0.0041 & 0.14 & Krejczy [53],Grange r[29], \\
\hline \multicolumn{6}{|l|}{ Cerebral haemorrhages } \\
\hline $\begin{array}{l}\text { Increase in the incidence of brain haemorrhage } \\
\text { through VKA }\end{array}$ & Normal & 4.00 & 0.22 & 4.00 & $\begin{array}{l}\text { Assumption, SD analogous to } \\
\text { Wolf [40] }\end{array}$ \\
\hline $\begin{array}{l}\text { Reduction in cerebral haemorrhages through NOAC } \\
\text { (compared with VKA) }\end{array}$ & Beta & 24.34211 & 35.02890 & 0.41 & Chatterjee [51], suppl., eFigure 3 \\
\hline Mortality cerebral haemorrhages & Beta & 37.422 & 39.578 & 0.486 & Fang [54] \\
\hline \multicolumn{6}{|l|}{ QALYS } \\
\hline Age decrement (per year) & Normal & -0.00029 & 0.0000225 & -0.00029 & Sullivan [55] \\
\hline with AF & Beta & 33.82 & 7.93 & 0.810 & $\begin{array}{l}\text { Gauthier: HTA Canada [56] citng } \\
\text { Sullivan et.al }[57,58]\end{array}$ \\
\hline with AF: reduction factor with VKA medication ${ }^{b}$ & Uniform & 0.953 & 1.000 & 0.987 & Shah \& Gage [59] (range), Gage et.al [60]. \\
\hline $\begin{array}{l}\text { with AF: reduction factor with NOAC } \\
\text { medication }{ }^{\mathrm{b}}\end{array}$ & Uniform & 0.990 & 0.998 & 0.994 & Shah \& Gage [59] (range), O’Brien, Gage [61] \\
\hline after cerebral haemorrhage, year 1 & Beta & 11.41332 & 17.19149 & 0.399 & Golicki [62] (ICD I61 result) \\
\hline after stroke, year 1 & Beta & 378.6275 & 304.81567 & 0.554 & Golicki [62] (ICD I63 result) \\
\hline after stroke: reduction in the year of the event & Normal & 0.103 & 0.008 & 0.103 & $\begin{array}{l}\text { Gauthier: HTA Canada [56], citing } \\
\text { Sullivan et.al [57]. }\end{array}$ \\
\hline $\begin{array}{l}\text { after stroke or cerebral haemor- rhage, subsequent } \\
\text { years b }\end{array}$ & Uniform & 0 & 0.5 & 0.12 & Shah \& Gage [59] (range) \\
\hline
\end{tabular}


Table 3 PSA distributions and parameters, base case values (Continued)

\begin{tabular}{llllll}
\hline Original name & Type & Param 1 & Param 2 & $\begin{array}{l}\text { Base } \\
\text { Case }\end{array}$ & Description \\
\hline Decrement for severe bleeding & Normal & $-0,092$ & 0.010 & $-0,092$ & $\begin{array}{l}\text { Gauthier: HTA Canada [56], Freeman [63], } \\
\text { Thomson [64] }\end{array}$ \\
Decrement for less severe bleeding & Normal & -0.013 & 0.001 & -0.013 & $\begin{array}{l}\text { Gauthier: HTA Canada [56], Freeman [63], } \\
\text { O'Brien [61] }\end{array}$ \\
\hline
\end{tabular}

${ }^{a}$ Values for men (75 years; if age-dependent) ${ }^{\mathrm{b}}$ Different average in EV (expected value) calculation

Parameters: by distribution type (Param1, Param2): Beta distribution (alpha, beta), Gamma distribution (alpha, lambda), Normal distribution (mean, standard deviation), Uniform distribuiton (min,max), Triangular distribution ( $\mathrm{min} /$ likeleliest/max)

The model considers cost and earnings components for the model sections screening, stroke prevention, acute stroke and cerebral haemorrhage and the costs they create, and the bleedings that occur as side effects of the preventive treatment with oral anticoagulants. Atrial fibrillation, stroke and cerebral haemorrhage trigger compensation payments in the current catalogue of the morbidity-oriented risk structure compensation scheme, which are (optionally) included in the model as earnings (see Table 5).

Screening: All participants of the screening ("Preventicus Heartbeats" scenario) firstly incur costs for the use of the "Preventicus Heartbeats" app. A sum of $€ 47.54$ including 19\% VAT is fixed in the base case as usage costs. The subsequent validation during a two-weekly measurement by means of a continuously measuring and telemetric Holter ECG and final assessment and diagnosis by a cardiologist costs $€ 297.50$ including 19\% VAT in the base case.

Stroke prevention with oral anticoagulants: the costs are a combined amount from the treatment with vitamin $\mathrm{K}$ antagonists (VKA, Marcumar ${ }^{\circ}$, daily cost of $€ 0.20$ ) and NOAC (new oral anticoagulants: Apixaban, Dabigatran, Rivaroxaban, Edoxaban, simplified assumption for the daily costs: $€ 3.00$ ). A Marcumar share of $29 \%$ is assumed, which corresponds to average annual costs (before discounts) of $€ 800$. There is only approximate information available about the rebates currently granted to health insurers. A rebate of $10 \%$ is used in the base case.

For the time after the NOAC patents expire (assumption: within 3 years after the start of the model), the model assumes that the NOAC costs decrease to $55 \%$ of the current level. This assumption is varied in the sensitivity calculations.

For stroke prevention, costs are incurred for out-patient treatment. Out-patient treatments are assumed in all four quarters, both for prevention with NOAC and for Prevention with VKA (fixed doctor's fee per quarter according to EBM catalogue number 0300: $€ 16.73$ for insured persons up to 75 years old, $€ 22.37$ for insured persons over 75 years old). Insured persons undergoing treatment with Phenprocoumon/Marcumar also incur a cost of $€ 0.75$ for the monthly measurement of the coagulation status (EBM catalogue no. 32110) [67].

Stroke costs: [3] created a model on the basis of the Erlangen register [68] of the lifetime costs of a stroke, taking into account the development of the German population between 2005 and 2025. The average lifetime cost amounted to $€ \mathbf{4 3 , 1 2 9}$, mainly determined by the outpatient part. The total cost amounted to $€ 18,517$ in the first year and $€ 5497$ in subsequent years. Due to the

Table 4 Age- and gender-dependent parameter values

\begin{tabular}{|c|c|c|c|c|c|c|c|c|c|}
\hline $\begin{array}{l}\text { Life } \\
\text { years }\end{array}$ & Gender & $\begin{array}{l}\text { Back-ground } \\
\text { mortality }\end{array}$ & $\begin{array}{l}\text { Stroke } \\
\text { mortality, year } \\
1\end{array}$ & $\begin{array}{l}\text { Stroke mortality, } \\
\text { subse-quent years }\end{array}$ & $\begin{array}{l}\text { AF } \\
\text { incidence }\end{array}$ & $\begin{array}{l}\text { AF } \\
\text { preval- } \\
\text { ence }\end{array}$ & $\begin{array}{l}\text { Undetect- } \\
\text { ed AF } \\
\text { (preval- } \\
\text { ence) }\end{array}$ & $\begin{array}{l}\text { Incidence of } \\
\text { strokes }\end{array}$ & $\begin{array}{l}\text { Incidence of intra-cranial } \\
\text { haemor-rhages }\end{array}$ \\
\hline \multirow[t]{2}{*}{65} & $M$ & $1.54 \%$ & $5.46 \%$ & $2.91 \%$ & $0.99 \%$ & $5.00 \%$ & $1.67 \%$ & $0.42 \%$ & $0.04 \%$ \\
\hline & $\mathrm{F}$ & $0.80 \%$ & $4.02 \%$ & $1.63 \%$ & $0.64 \%$ & $2.72 \%$ & $0.91 \%$ & $0.27 \%$ & $0.02 \%$ \\
\hline \multirow[t]{2}{*}{70} & M & $2.24 \%$ & $7.82 \%$ & $4.21 \%$ & $1.39 \%$ & $7.80 \%$ & $2.60 \%$ & $0.63 \%$ & $0.06 \%$ \\
\hline & $\mathrm{F}$ & $1.22 \%$ & $6.01 \%$ & $2.47 \%$ & $1.06 \%$ & $4.97 \%$ & $1.66 \%$ & $0.45 \%$ & $0.04 \%$ \\
\hline \multirow[t]{2}{*}{75} & M & $3.40 \%$ & $11.53 \%$ & $6.34 \%$ & $1.89 \%$ & $11.37 \%$ & $3.79 \%$ & $1.03 \%$ & $0.10 \%$ \\
\hline & $\mathrm{F}$ & $1.91 \%$ & $9.15 \%$ & $3.83 \%$ & $1.58 \%$ & $8.09 \%$ & $2.70 \%$ & 0.99\% & $0.07 \%$ \\
\hline \multirow[t]{2}{*}{80} & M & $5.86 \%$ & $18.72 \%$ & $10.67 \%$ & $2.39 \%$ & $14.57 \%$ & $4.86 \%$ & $1.36 \%$ & $0.17 \%$ \\
\hline & $\mathrm{F}$ & $3.84 \%$ & $17.15 \%$ & $7.57 \%$ & $2.14 \%$ & $11.29 \%$ & $3.77 \%$ & $1.26 \%$ & $0.12 \%$ \\
\hline \multirow[t]{2}{*}{85} & M & $10.75 \%$ & $30.83 \%$ & $18.79 \%$ & $3.01 \%$ & $16.92 \%$ & $5.64 \%$ & $2.42 \%$ & $0.29 \%$ \\
\hline & $\mathrm{F}$ & $7.72 \%$ & $30.24 \%$ & $14.64 \%$ & $2.77 \%$ & $13.42 \%$ & $4.47 \%$ & $2.01 \%$ & $0.21 \%$ \\
\hline
\end{tabular}


Table 5 Cost parameters

\begin{tabular}{|c|c|c|}
\hline Parameter & Value $(€)$ & Comment \\
\hline \multicolumn{3}{|l|}{ Preventicus screening } \\
\hline Preventicus app & 47.54 & \\
\hline Assessment and diagnosis & 297.50 & \\
\hline Outpatient treatment & & Source: EBM catalogue [67] \\
\hline GP consultation, age below 76 & 16.73 & EBM catalogue no. 0300 \\
\hline GP consultation, age 76 or above & 22.37 & \\
\hline INR coagulation measurement & 0.75 & EBM catalogue no. 32110 \\
\hline Medication: VKA & 0.20 & Yearly costs: $73 €$ \\
\hline Medication: NOAC & 3.00 & Yearly costs: $1095 €$ \\
\hline NOAC prices after patent expiration (\% of current prices) & $55 \%$ & Reduced yearly costs: $602 €$ \\
\hline Medication: rebate granted & $10 \%$ & Assumption \\
\hline \multicolumn{3}{|l|}{ Strokes / ICH } \\
\hline Stroke costs, year 1 & 21.060 & 2018 costs, inflated data based on \\
\hline Stroke costs, follow-up years & 6.211 & Kolominsky-Rabas [3] \\
\hline Inflation factor 2006-2018 & $113.7 \%$ & Statistisches Bundesamt \\
\hline $\mathrm{ICH}$, percentage of stroke costs & $150 \%$ & Assumption \\
\hline \multicolumn{3}{|l|}{ Bleeding } \\
\hline Minor bleeding & 50 & cost assumption by [44] \\
\hline Major bleeing & 2.050 & DRG catalogue numbers G70A-C and G46B) \\
\hline Risk structure compensation & & Source: 2018 HMG catalogue values \\
\hline HMG 092 (Arrhythmias) & 1.249 & \\
\hline HMG 092 decrease after NOAC patent expiration & $90 \%$ & $\begin{array}{l}\text { per year. Assumption: compensation will bedecreased because } \\
\text { of lower medication costs until a minimum of } 700 € \text { is reached. }\end{array}$ \\
\hline HMG 096 (Ischaemic strokes) & 2.248 & \\
\hline HMG 095 (ICH) & 5.831 & \\
\hline
\end{tabular}

Table 6 Parameters of the deterministic sensitivity analysis

\begin{tabular}{|c|c|c|c|}
\hline \multirow[b]{2}{*}{ Model parameters } & \multicolumn{2}{|c|}{ Sensitivity analysis } & \multirow{2}{*}{$\begin{array}{l}\text { Base } \\
\text { case }\end{array}$} \\
\hline & $\min$ & $\max$ & \\
\hline General Starting age & 65 & 85 & 75 \\
\hline Undetected AF in \% detected AF & $10.0 \%$ & $70.0 \%$ & $33.3 \%$ \\
\hline Increase in background mortality, AF subpopulation & $0 \%$ & $75.0 \%$ & $25.0 \%$ \\
\hline Sensitivity Preventicus screening & $85.0 \%$ & $100.0 \%$ & $91.6 \%$ \\
\hline Specificity Preventicus screening & $85.0 \%$ & $100.0 \%$ & $99.6 \%$ \\
\hline Positively validated screening results (after flutter ECG) & $75.0 \%$ & $95.0 \%$ & $35 \%$ \\
\hline Increased incidence of spontaneous AF, AF population & 1.0 & 3.0 & 1.0 \\
\hline Prevention Reduction stroke rate with prevention & $40.0 \%$ & $90.0 \%$ & $70.0 \%$ \\
\hline Increased stroke rate with AF without prevention & 2.0 & 5.0 & 4.2 \\
\hline Marcumar proportion in OAC medication & $10.0 \%$ & $50.0 \%$ & $29.0 \%$ \\
\hline Increase in the incidence of brain haemorrhage through VKA & 3.0 & 10.0 & 4.0 \\
\hline Reduction in cerebral haemorrhage through NOAC (compared with VKA) & $35.0 \%$ & $55.0 \%$ & $41.0 \%$ \\
\hline \multicolumn{4}{|l|}{ Costs, profits } \\
\hline Scaling factor screening costs & 0.5 & 5.0 & 1.0 \\
\hline Prices OAC after patent expires (actual: 100\%) & $40 \%$ & $100 \%$ & $55 \%$ \\
\hline Clawback (rebate granted to health insurers?) & $0.0 \%$ & $25.0 \%$ & $10.0 \%$ \\
\hline Years until patent expiry & 2 & 10 & 3 \\
\hline Scaling factor stroke 1 - costs & 0.5 & 1.5 & 1.0 \\
\hline Scaling factor costs cerebral haemorrhage & 0.75 & 3.0 & 1.0 \\
\hline Scaling factor RSA & 0.0 & 1.25 & 1.0 \\
\hline Discount rate for costs & $1.0 \%$ & $5.0 \%$ & $3.0 \%$ \\
\hline
\end{tabular}


temporal distance from index year 2006, higher costs must be assumed. Based on the consumer price index for healthcare costs [69] a cost increase of $13.7 \%$ must be assumed for the period 2006-2018. The total cost of the base case amounts to $€ 21,060$ in the first year and $€ 6231$ in subsequent years.

Cost of intracranial haemorrhage (ICH): we were not able to identify any study that quantifies the costs for the German healthcare system. DRG statistics of the Institute für Entgeltwesen im Gesundheitswesen ([70] [Institute for compensation in healthcare]) show that, when comparing the ICD10 Figs. I61 (hemorrhagic strokes) and I63 (ischemic strokes), the case-by-case hospital costs for cerebral bleeding is 1.8 times as much as the case-by-case costs of ischemic strokes. For this model, 1.5 times the case-by-case cost of an ischaemic stroke is used. The assumption is varied in a sensitivity analysis.

\section{Cost of bleedings}

- Severe bleedings: an average cost rate from the DRG costs for gastrointestinal bleeding (DRG catalogue numbers G70A-C and G46B) is used. This amounts to a cost of $€ 2025$ per bleeding.

- Less severe bleedings: to simplify, the cost assumption by [53] was adopted for the amount of $€ 50$ per bleeding.

Refunds as part of the risk structure compensation scheme: the reimbursement amounts incurred as part of the morbidity-oriented risk structure compensation scheme, are published by the German Federal Insurance Office. This is based on the reimbursement amounts for compensation year 2017 [71]. It is assumed that the three morbidity groups concerned will also remain part of the risk structure compensation scheme in the long term. The morbidity groups concerned are:

- Atrial fibrillation (homogeneous morbidity group HMG 092): the compensation amount is $€ 1249$ for in-patient treatment or treatment for at least two quarters. It is assumed that both prevention with VKA and prevention with NOAC are reimbursed. For the time after the NOAC patent has expired, it is assumed that the compensation amount decreases annually by $10 \%$, until the reimbursement level before NOAC was implemented has been reached (approx. 700 euros before 2010).

- Strokes (HMG 096): €2248, for which a main hospital diagnosis is required. This should always be the case for acute or subsequent strokes.

- Cerebral haemorrhage (HMG 095): €5831. The requirements are the same as those for a stroke.

- The costs are discounted by $3 \%$ per year.
Quality of life: To assess the effectiveness of the measure, the model uses the change in quality-adjusted life years (QALY). QALYs reflect the state of health in each year, using Value 1 for full health and Value 0 for death (see e.g. [35]). The following assumptions are made for the model:

- QALY in the presence of arrhythmia: 0.81 (source: [56], citing [57]. QALY decrement based on the EQ5D median scores for cardiac arrhythmias [58])

- QALY decrements for aging have been estimated by [55] (Fig. 1). The base case assumes a QALY decrement of 0.00029 per year exceeding the age of 65 years.

- Drop in arrhythmia QALYs through stroke prevention: use of factor 0.987 for VKA treatment (Source: $[59,60]$ and 0.994 for NOAC treatment on the arrhythmia QALY (source: [59, 61])

- QALY after initial stroke event: 0.55 (source: [62])

- QALY after subsequent stroke event: 0.12 (source: [59])

- QALY after intracranial haemorrhage, initial event: 0.399 (source: [62]) Subsequent events are evaluated as for strokes.

- QALY decrements for bleedings: in cases of severe bleeding, 0.092 is deducted in the year of the bleeding (sources: $[56,63,64]$ ). In cases of mild bleeding the decrement is 0.013 in the year of the bleeding (sources: $[56,61,63]$ )

- QALYs are discounted by 3\% per year.

Tables 3 through 6 summarize the model parameters. Table 3 lists the base case parameter values and PSA distribution assumptions. Table 4 lists the age- and gender-dependent parameter values. Table 5 summarizes the unit cost parameters of the model and Table 6 lists the parameters which have been examined in the deterministic sensitivity analyses.

\footnotetext{
Abbreviations

AF: Atrial Fibrillation; ATT, NOATT: Anti-thrombotic treatment resp. No antithrombotic treatment; Cl: Confidence interval; DRG: Diagnosis related groups; EBM: Unified standard of evaluation, German reimbursement catalogue, (German: Einheitlicher Bewertungsmaßstab); ECG: Electrocardiogram; EV: Expected value; HIQA: Health Information and quality authority (Ireland); HMG: Homogeneous morbidity groups; HTA: Health technology assessment; ICD: International classification of diseases; ICER: Incremental cost-

effectiveness ratio; ICH: Intracerebral hemorrhage; NICE: National institute for health and care excellence (England); NOAC: Novel (direct) oral anticoagulants; OAC: Oral anticoagulants; QALY: Quality adjusted life years; RSC/RSA: Risk structure compensation scheme /(German:

Risikostrukturausgleich); SD, Std. Dev.: Standard deviation; SGB: German social act (German: Sozialgesetzbuch); VAT: Value added tax; VKA: Vitamin K antagonists
}

Acknowledgments

None. 


\section{Authors' contributions}

RB was the lead author responsible for the initial draft of the manuscript. which was critically revised by all authors. AM and JMS were involved in the study design.

of the economic analysis. AM and SW performed the statistical analyses. All authors participated in the whole of the study design. All authors read and approved the final manuscript.

\section{Funding}

The economic model was funded by Preventicus $\mathrm{GmbH}$, Tatzendpromenade 2, D-07745 Jena, Germany. The funding body was not involved in the design of the study, the collection, analysis, and interpretation of data, and writing the manuscript.

\section{Availability of data and materials}

All data generated or analyzed for the economic model are included in this published article.

\section{Ethics approval and consent to participate}

The analysis was only based on published results. Thus, an ethical approval or consent to participate was not necessary.

\section{Consent for publication}

Not applicable.

\section{Competing interests}

The authors declare that they have no competing interests.

\section{Author details}

${ }^{1}$ Ulm Herzklinik, Krankenhausstraße 5, 89231 Ulm, Germany. ${ }^{2}$ Analytic Services GmbH, Jahnstr. 34c, 80469 Munich, Germany. ${ }^{3}$ St. Bernward GmbH, Friedrich-Kirsten-Straße 40, 22391 Hamburg, Germany. ${ }^{4}$ Universität Hannover, Welfengarten 1, 30167 Hannover, Germany.

\section{Received: 23 October 2019 Accepted: 19 May 2020}

\section{Published online: 09 June 2020}

\section{References}

1. Statistisches Bundesamt. Genesis Online-Datenbank, Table 23631-0001: Krankheitskosten. Deutschland: Jahre, Krankheitsdiagnosen (ICD-10); 2015. (Accessed 23 Oct 2018).

2. Heuschmann P, Busse $\mathrm{O}$, Wagner $\mathrm{M}$, Endres $\mathrm{M}$, Villringer $\mathrm{A}$, Röther J, et al. Schlaganfallhäufigkeit und Versorgung von Schlaganfallpatienten in Deutschland. Akt Neurol. 2010;37:333-40.

3. Kolominsky-Rabas PL, Heuschmann PU, Marschall D, Emmert M, Baltzer N, Neundörfer B, et al. Lifetime cost of ischemic stroke in Germany: results and national projections from a population-based stroke registry: the Erlangen Stroke Project. Stroke. 2006:37:1179-83.

4. Busch MA, Schienkiewitz A, Nowossadeck E, Gößwald A. Prävalenz des Schlaganfalls bei Erwachsenen im Alter von 40 bis 79 Jahren in Deutschland: Ergebnisse der Studie zur Gesundheit Erwachsener in Deutschland (DEGS1). Bundesgesundheitsblatt Gesundheitsforschung Gesundheitsschutz. 2013;56:656-60.

5. Fuster V, Rydén LE, Cannom DS, Crijns HJ, Curtis AB, Ellenbogen KA, et al. ACC/AHA/ESC 2006 guidelines for the management of patients with atrial fibrillation--executive summary: a report of the American College of cardiology/American heart association task force on practice guidelines and the European society of cardiology committee for practice guidelines (writing committee to revise the 2001 guidelines for the management of patients with atrial fibrillation). J Am Coll Cardiol. 2006;48:854-906.

6. Perings C, Hennersdorf M, Vester EG, Weirich J, Strauer BE. Pathophysiologie, Epidemiologie und Komplikationen des Vorhofflimmerns. Der Internist. 1998;39:2-11.

7. Kannel WB, Wolf PA, Benjamin EJ, Levy D. Prevalence, incidence, prognosis, and predisposing conditions for atrial fibrillation: population-based estimates 11Reprints are not available. Am J Cardiol. 1998:82:2N-9N.

8. Benjamin EJ, Wolf PA, D'Agostino RB, Silbershatz H, Kannel WB, Levy D Impact of atrial fibrillation on the risk of death: the Framingham Heart Study. Circulation. 1998;98:946-52

9. Thrall G, Lane D, Carroll D, Lip GYH. Quality of life in patients with atrial fibrillation: a systematic review. Am J Med. 2006;1 19:448.e1-19.
10. Wang TJ, Larson MG, Levy D, Vasan RS, Leip EP, Wolf PA, et al. Temporal relations of atrial fibrillation and congestive heart failure and their joint influence on mortality: the Framingham Heart Study. Circulation. 2003;107: 2920-5.

11. Benkert D, Theres H, Wasem J, Aidelsburger P. Direkte Kosten in der Diagnostik und Behandlung von Patienten mit symptomatischem Vorhofflimmern in Deutschland. Pharmacoeconomics Ger Res Articles. 2009; 7:15-27.

12. Reinhold T, Rosenfeld S, Müller-Riemenschneider F, Willich SN, Meinertz T, Kirchhof $\mathrm{P}$, et al. Patienten mit Vorhofflimmern in Deutschland. Charakteristika, Ressourcenverbrauch und Kosten. Herz. 2012;37:534-42.

13. Bramlage $K$, Thoenes $M$, Tebbe $U$, Bramlage $P$, Wasem J. Vorhofflimmern in Deutschland - Epidemiologie, Diagnostik, Therapie und Kosten. Med Monatschr Pharm. 2013;36:215-24.

14. Go AS, Hylek EM, Phillips KA, Chang Y, Henault LE, Selby JV, et al. Prevalence of diagnosed atrial fibrillation in adults: national implications for rhythm management and stroke prevention: the AnTicoagulation and Risk Factors in Atrial Fibrillation (ATRIA) Study. JAMA. 2001;285:2370-5.

15. Svennberg E, Engdahl J, Al-Khalili F, Friberg L, Frykman V, Rosenqvist M. Mass Screening for Untreated Atrial Fibrillation: The STROKESTOP Study. Circulation. 2015:131:2176-84.

16. Panisello-Tafalla A, Clua-Espuny JL, Gil-Guillen VF, González-Henares A, Queralt-Tomas ML, López-Pablo C, et al. Results from the Registry of Atrial Fibrillation (AFABE): Gap between Undiagnosed and Registered Atrial Fibrillation in Adults--Ineffectiveness of Oral Anticoagulation Treatment with VKA. Biomed Res Int. 2015;2015:134756.

17. Clua-Espuny JL, Lechuga-Duran I, Bosch-Princep R, Roso-Llorach A, PaniselloTafalla A, Lucas-Noll J, et al. Prevalence of undiagnosed atrial fibrillation and of that not being treated with anticoagulant drugs: the AFABE study. Rev Esp Cardiol (Engl Ed). 2013:66:545-52.

18. Andersson T, Magnuson A, Bryngelsson I-L, Frøbert O, Henriksson KM, Edvardsson N, et al. All-cause mortality in 272,186 patients hospitalized with incident atrial fibrillation 1995-2008: a Swedish nationwide long-term casecontrol study. Eur Heart J. 2013:34:1061-7.

19. Nieuwlaat R, Capucci A, Camm AJ, Olsson SB, Andresen D, Davies DW, et al. Atrial fibrillation management: a prospective survey in ESC member countries: the Euro Heart Survey on Atrial Fibrillation. Eur Heart J. 2005;26:2422-34.

20. Spratt N, Wang Y, Levi C, Ng K, Evans M, Fisher J. A prospective study of predictors of prolonged hospital stay and disability after stroke. J Clin Neurosci. 2003;10:665-9.

21. Savelieva I, Bajpai A, Camm AJ. Stroke in atrial fibrillation: update on pathophysiology, new antithrombotic therapies, and evolution of procedures and devices. Ann Med. 2007:39:371-91.

22. Ruigómez A, Johansson $\mathrm{S}$, Wallander MA, Rodríguez LAG. Incidence of chronic atrial fibrillation in general practice and its treatment pattern. J Clin Epidemiol. 2002;55:358-63.

23. Hart RG, Benavente O, McBride R, Pearce LA. Antithrombotic therapy to prevent stroke in patients with atrial fibrillation: a meta-analysis. Ann Intern Med. 1999:131:492-501.

24. van Walraven C, Hart RG, Singer DE, Laupacis A, Connolly S, Petersen P, et al. Oral anticoagulants vs aspirin in nonvalvular atrial fibrillation: an individual patient meta-analysis. JAMA. 2002;288:2441-8.

25. Kirchhof P, Benussi S, Kotecha D, Ahlsson A, Atar D, Casadei B, et al. 2016 ESC Guidelines for the management of atrial fibrillation developed in collaboration with EACTS. Eur Heart J. 2016:37:2893-962.

26. López-López JA, Sterne JAC, Thom HHZ, Higgins JPT, Hingorani AD, Okoli $\mathrm{GN}$, et al. Oral anticoagulants for prevention of stroke in atrial fibrillation: systematic review, network meta-analysis, and cost effectiveness analysis. BMJ. 2017;359:5058.

27. Camm AJ, Lip GYH, de Caterina R, Savelieva I, Atar D, Hohnloser SH, et al. 2012 focused update of the ESC Guidelines for the management of atrial fibrillation: an update of the 2010 ESC Guidelines for the management of atrial fibrillation. Developed with the special contribution of the European Heart Rhythm Association. Eur Heart J. 2012:33:2719-47.

28. Rocket AF Study Investigators. Rivaroxaban-once daily, oral, direct factor Xa inhibition compared with vitamin $\mathrm{K}$ antagonism for prevention of stroke and Embolism Trial in Atrial Fibrillation: rationale and design of the ROCKET AF study. Am Heart J. 2010:159:340-347.e1.

29. Granger CB, Alexander JH, McMurray JJV, Lopes RD, Hylek EM, Hanna M, et al. Apixaban versus warfarin in patients with atrial fibrillation. $N$ Engl J Med. 2011;365:981-92. 
30. Connolly SJ, Ezekowitz MD, Yusuf S, Eikelboom J, Oldgren J, Parekh A, et al. Dabigatran versus warfarin in patients with atrial fibrillation. N Engl J Med. 2009;361:1139-51.

31. Brasier N, Raichle CJ, Dörr M, Becke A, Nohturfft V, Weber S, et al. Detection of atrial fibrillation with a smartphone camera: first prospective, international, two-centre, clinical validation study (DETECT AF PRO). Europace. 2019;21:41-7.

32. Koenig N, Seeck A, Eckstein J, Mainka A, Huebner T, Voss A, et al. Validation of a New Heart Rate Measurement Algorithm for Fingertip Recording of Video Signals with Smartphones. Telemed J E Health. 2016;22:631-6.

33. Drummond MF, Sculpher M, Torrance GW, O'Brien BJ, Stoddart GL. Methods for the economic evaluation of health care programmes. 3rd ed. Oxford: Oxford Univ. Press; 2007.

34. Schöffski O, Claes C. Das Design einer gesundheitsökonomischen Studie. In: Schöffski O, Schulenburg J-MG, editors. Gesundheitsökonomische Evaluationen: Studienausgabe. Berlin, Heidelberg, s.l.: Springer Berlin Heidelberg; 2002. p. 51-122.

35. Schöffski O, Greiner W. Das QALY-Konzept zur Verknüpfung von Lebensqualitätseffekten mit ökonomischen Daten. In: Schöffski O, Schulenburg J-MG, editors. Gesundheitsökonomische Evaluationen: Studienausgabe. Berlin, Heidelberg, s.l.: Springer Berlin Heidelberg; 2002. p. 367-99.

36. Aronsson M, Svennberg E, Rosenqvist M, Engdahl J, Al-Khalili F, Friberg L, et al. Cost-effectiveness of mass screening for untreated atrial fibrillation using intermittent ECG recording. Europace. 2015;17:1023-9.

37. Welton NJ, McAleenan A, Thom HH, Davies P, Hollingworth W, Higgins JP, et al. Screening strategies for atrial fibrillation: a systematic review and costeffectiveness analysis: Health Technology Assessment. Health Technol Assess. 2017;21:1-236.

38. Health Information and Quality Authority. Health technology assessment (HTA) of a national screening programme for atrial fibrillation in primarycare. Dublin; 2015. http://www.hiqa.ie/sites/default/files/2017-02/ HTA-of-Screening-for-Atrial-Fibrillation.pdf.

39. Pletscher M, Plessow R, Eichler K, Wieser S. Cost-effectiveness of dabigatran for stroke prevention in atrial fibrillation in Switzerland. Swiss Med Wkly. 2013;143:w13732.

40. Wolf PA, Abbott RD, Kannel WB. Atrial fibrillation as an independent risk factor for stroke: the Framingham Study. Stroke. 1991;22:983-8.

41. Herman WH, Hoerger TJ, Brandle M, Hicks K, Sorensen S, Zhang P, et al. The Cost-Effectiveness of Lifestyle Modification or Metformin in Preventing Type 2 Diabetes in Adults with Impaired Glucose Tolerance. Ann Intern Med. 2005; 142:323-32

42. Lowres N, Neubeck L, Redfern J, Freedman SB. Screening to identify unknown atrial fibrillation. A systematic review. Thromb Haemost. 2013;110:213-22.

43. Wilke T, Groth A, Mueller S, Pfannkuche M, Verheyen F, Linder R, et al. Incidence and prevalence of atrial fibrillation: an analysis based on 8.3 million patients. Europace. 2013:15:486-93.

44. Wachter R, Gröschel K, Gelbrich G, Hamann GF, Kermer P, Liman J, et al. Holter-electrocardiogram-monitoring in patients with acute ischaemic stroke (Find-AF RANDOMISED ): an open-label randomised controlled trial. Lancet Neurol. 2017:16:282-90.

45. Statistisches Bundesamt. Sterbetafel (Periodensterbetafel) 2015: Deutschland, Jahre, Geschlecht, Vollendetes Alter: URL: https://www-genesis.destatis.de/ genesis/online/link/tabelleErgebnis/12621-0001. 2015

46. Bronnum-Hansen $H$, Davidsen $M$, Thorvaldsen P. Long-Term Survival and Causes of Death After Stroke. Stroke. 2001;32:2131-6.

47. WMT J, CJM K, Brouwers PJAM, Kappelle LJ, Vaartjes I. Time trends in incidence, case fatality, and mortality of intracerebral hemorrhage. Neurology. 2015;85:1318-24.

48. Hardie K, Hankey GJ, Jamrozik K, Broadhurst RJ, Anderson C. Ten-year risk of first recurrent stroke and disability after first-ever stroke in the Perth Community Stroke Study. Stroke. 2004;35:731-5.

49. Kolominsky-Rabas PL, Sarti C, Heuschmann PU, Graf C, Siemonsen S, Neundoerfer B, et al. A Prospective Community-Based Study of Stroke in Germany The Erlangen Stroke Project (ESPro) Incidence and Case Fatality at 1, 3, and 12 Months. Stroke. 1998;29:2501-6.

50. Friberg $L$, Rosenqvist M, Lip GYH. Evaluation of risk stratification schemes for ischaemic stroke and bleeding in 182678 patients with atrial fibrillation: the Swedish Atrial Fibrillation cohort study. Eur Heart J. 2012;33:1500-10.

51. Chatterjee S, Sardar P, Biondi-Zoccai G, Kumbhani DJ. New oral anticoagulants and the risk of intracranial hemorrhage: traditional and
Bayesian meta-analysis and mixed treatment comparison of randomized trials of new oral anticoagulants in atrial fibrillation. JAMA Neurol. 2013;70: 1486-90.

52. Wolf PA, Mitchell JB, Baker CS, Kannel WB, D'Agostino RB. Impact of atrial fibrillation on mortality, stroke, and medical costs. Arch Intern Med. 1998; 158:229-34.

53. Krejczy M, Harenberg J, Marx S, Obermann K, Frölich L, Wehling M. Comparison of cost-effectiveness of anticoagulation with dabigatran, rivaroxaban and apixaban in patients with non-valvular atrial fibrillation across countries. J Thromb Thrombolysis. 2014;37:507-23.

54. Fang MC, Go AS, Chang Y, Hylek EM, Henault LE, Jensvold NG, et al. Death and disability from warfarin-associated intracranial and extracranial hemorrhages. Am J Med. 2007;120:700-5.

55. Sullivan PW, Lawrence WF, Ghushchyan V. A national catalog of preferencebased scores for chronic conditions in the United States. Med Care. 2005:43: 736-49.

56. Canadian Agency for Drugs and Technologies in Health. Antithrombotic Agents for the Prevention of Stroke and Systemic Embolism in Patients With Atrial Fibrillation. CADTH Technol Overv. 2013;3:e3202.

57. Sullivan PW, Arant TW, Ellis SL, Ulrich $H$. The cost effectiveness of anticoagulation management services for patients with atrial fibrillation and at high risk of stroke in the US. Pharmacoeconomics. 2006:24:1021-33.

58. Sullivan PW, Ghushchyan V. Preference-Based EQ-5D Index Scores for Chronic Conditions in the United States. Med Decis Making. 2006:26:410-20.

59. Shah SV, Gage BF. Cost-effectiveness of dabigatran for stroke prophylaxis in atrial fibrillation. Circulation. 2011;123:2562-70.

60. Gage BF, Cardinalli AB, Owens DK. The effect of stroke and stroke prophylaxis with aspirin or warfarin on quality of life. Arch Intern Med. 1996; 156:1829-36.

61. O'Brien CL, Gage BF. Costs and effectiveness of ximelagatran for stroke prophylaxis in chronic atrial fibrillation. JAMA. 2005;293:699-706.

62. Golicki D, Niewada M, Buczek J, Karlińska A, Kobayashi A, Janssen MF, et al. Validity of EQ-5D-5L in stroke. Qual Life Res. 2015;24:845-50.

63. Freeman JV, Zhu RP, Owens DK, Garber AM, Hutton DW, Go AS, et al. Costeffectiveness of dabigatran compared with warfarin for stroke prevention in atrial fibrillation. Ann Intern Med. 2011;154:1-11.

64. Thomson R, Parkin D, Eccles M, Sudlow M, Robinson A. Decision analysis and guidelines for anticoagulant therapy to prevent stroke in patients with atrial fibrillation. Lancet. 2000;355:956-62.

65. Friberg $L$, Hammar N, Pettersson H, Rosenqvist M. Increased mortality in paroxysmal atrial fibrillation: report from the Stockholm Cohort-Study of Atrial Fibrillation (SCAF). Eur Heart J. 2007:28:2346-53.

66. Huisman MV, Rothman KJ, Paquette M, Teutsch C, Diener H-C, Dubner SJ, et al. The Changing Landscape for Stroke Prevention in AF: Findings From the GLORIA-AF Registry Phase 2. J Am Coll Cardiol. 2017;69:777-85.

67. Bundesvereinigung K. Einheitlicher Bewertungsmaßstab (EBM): Stand: 1 Berlin: Quartal 2018; 2018.

68. Kolominsky-Rabas PL, Weber M, Gefeller O, Neundoerfer B, Heuschmann PU. Epidemiology of ischemic stroke subtypes according to TOAST criteria: incidence, recurrence, and long-term survival in ischemic stroke subtypes: a population-based study. Stroke. 2001;32:2735-40.

69. Statistisches Bundesamt. Verbraucherpreise für Deutschland, 2010=100: Abteilung 06: Gesundheitspflege. 2018. https://www.destatis.de/DE/ ZahlenFakten/GesamtwirtschaftUmwelt/Preise/Verbraucherpreisindizes/ Tabellen_NerbraucherpreiseKategorien.html?cms_gtp=145116_list\%253D2.

70. InEK - Institut für das Entgeltwesen im Krankenhaus. G-DRG-Browser 2016 2017. 2018. https://www.g-drg.de/Datenbrowser_und_Begleitforschung/ Datenveroeffentlichung_gem._21_KHEntgG/G-DRG-Browser_2016_2017. Accessed 23 Oct 2018

71. Bundesversicherungsamt. Festlegung der zu berücksichtigenden Krankheiten nach § 31 Abs. 4 Satz 1 RSAV (29.02 2016). 2017.

\section{Publisher's Note}

Springer Nature remains neutral with regard to jurisdictional claims in published maps and institutional affiliations. 